"This is the pre-peer reviewed version of the following articleKhaleva E, Gridneva Z, Geddes DT, et al. Transforming growth factor beta in human milk and allergic outcomes in children: A systematic review. Clin Exp Allergy. 2019;00:1-13. https ://doi.org/10.1111/cea.13409, which has been published in final form at https://onlinelibrary.wiley.com/doi/abs/10.1111/cea.13409. This article may be used for non-commercial purposes in accordance with Wiley Terms and Conditions for Use of Self-Archived Versions."

\title{
Transforming growth factor beta in human milk and allergic outcomes in children: a systematic
} review.

Ekaterina Khaleva ${ }^{1,2,{ }^{*}}$ and Zoya Gridneva ${ }^{2,3, *}$, Donna T. Geddes ${ }^{2,3}$, Wendy H. Oddy ${ }^{4}$, Silvia Colicino ${ }^{5}$, Oleg Blyuss ${ }^{6,7}$, Robert Boyle $2,8,9$, John Warner ${ }^{2,8,10}$, Daniel Munblit $2,8,11,12$

${ }^{1}$ University of Southampton, Southampton, SO17 1BJ, UK; ${ }^{2}$ inVIVO Planetary Health, Research Group of the Worldwide Universities Network, West New York, NJ 07093-9992, USA; ${ }^{3}$ School of Molecular Sciences, The University of Western Australia, Perth, 6009, WA, Australia; ${ }^{4}$ Nutritional Epidemiology, Menzies Institute for Medical Research, University of Tasmania, Hobart, TAS, 7000, Australia; ${ }^{5}$ The National Heart and Lung Institute, Imperial College London, SW3 6LR, UK; ${ }^{6}$ Wolfson Institute of Preventive Medicine, Queen Mary University of London, EC1M 6BQ, UK; ${ }^{7}$ Department of Applied Mathematics, Lobachevsky State University of Nizhny Novgorod, Nizhny Novgorod, 603022, Russia; ${ }^{8}$ Department of Paediatrics, Imperial College London, London W2 1NY, UK; ${ }^{9}$ Centre of Evidence-based Dermatology, University of Nottingham, UK; ${ }^{10}$ Paediatrics and NIHR Collaboration for Leadership in Applied Health Research and Care for NW London, London, UK; ${ }^{11}$ Faculty of Pediatrics, I. M. Sechenov First Moscow State Medical University, Moscow 119991, Russia; ${ }^{12}$ Solov'ev Research and Clinical Center for Neuropsychiatry, Moscow 115419, Russia.

Correspondence: Daniel Munblit, MD, PhD, Department of Paediatrics, Department of Medicine, Imperial College London, London, UK. Phone: +447898257151; Email: daniel.munblit08@imperial.ac.uk

* The first two authors contributed equally to this work 
27

28

29

30

31

32

33

34

35

36

37

38

39

40

41

42

43

44

45

46

47

48

49

50

51

52

53

54

55

56

57

58

59

60

61

62

63

64

65

66

67

\begin{abstract}
Funding sources
This research did not receive any specific grant from funding agencies in the public, commercial, or not-for-profit sectors. The authors declare that Medela AG provided an unrestricted research grant to DT Geddes, from which salaries to DT Geddes and Z. Gridneva were paid. JO. Warner is employed by Imperial College through the National Institute of Health Research (NIHR) Collaboration for Leadership in Applied Health Research and Care (CLAHRC) for NW London. The views expressed are those of the author(s) and not necessarily those of the UK National Health Service, the NIHR or the Department of Health. WH. Oddy is employed as a Professorial Research Fellow at the Menzies Institute for Medical Research at the University of Tasmania, Australia. RJ. Boyle is supported by a National Institute for Health Research Biomedical Research Centre (BRC), have received research grant income from Danone in relation to studies of the value of prebiotics in allergy prevention. He has received funding to evaluate Airsonette, a temperature-controlled laminar airflow for asthma, and given paid lectures for these companies. D. Munblit has received consultancy payment from Dairy Goat Co-Operative (NZ) Ltd. and has given paid lectures for Merck Sharp \& Dohme (MSD) and Bayer. O. Blyuss acknowledges support from Russia under Grant No. 074-02-2018330. Other authors do not report any financial interest. The funding sponsors had no role in the design of the study; in the collection, analyses, or interpretation of data; in the writing of the manuscript, or in the decision to publish the results.
\end{abstract}

Total word count: 4995

\title{
Abstract
}

Background: Human milk (HM) transforming growth factor beta (TGF- $\beta$ ) is critical for inflammation regulation and oral tolerance promotion. Previous reports suggested that variations in HM TGF- $\beta$ levels are associated with allergic outcomes.

Objective: We undertook a systematic review (PROSPERO 2017 CRD42017069920) to reassess the evidence on the relationships between HM TGF- $\beta$ and allergic outcomes in children.

Methods: Electronic bibliographic databases (MEDLINE, EMBASE, Cochrane Library) were systematically searched. Two independent reviewers screened reference lists, extracted the data and assessed risk of bias using the National Institute for Clinical Excellence methodological checklist.

Results: A total of 21 studies were identified. Sixteen studies assessed relationships between HM TGF- $\beta$ and risk of eczema; 14, allergic sensitisation; 9, wheezing/asthma; 6, food allergy; 3, allergic rhinitis/conjunctivitis. Five cohorts (5/18, 28\%) reported a protective effect of TGF- $\beta 1$, while 3 (3/10, $30 \%$ ) suggested increased risk of allergic outcomes development and 1 (1/10,10\%), a protective effect of TGF- $\beta 2$ on eczema. Meta-analysis was not possible due to significant heterogeneity in methodology, age of outcome assessment and differing statistical approaches. 71\% (15/21) of studies carried a high risk of bias.

Conclusion: In contrast with previous findings we did not find strong evidence of associations between HM TGF- $\beta$ and allergic outcomes. Differences in studies' methodology and outcomes do not allow unconditional rejection or acceptance of the hypothesis that HM TGF- $\beta$ influences the risk of allergy development. Future studies on diverse populations employing standardised methods, accurate phenotyping of outcomes and evaluation of the effect of TGF- $\beta$ in combination with other HM immune markers, microbiome and oligosaccharides are required.

\section{Key Messages}

- $\quad$ Basic science evidence suggests that human milk TGF- $\beta$ is particularly important for oral tolerance development, with previous reports finding associations between TGF- $\beta$ and immunological outcomes.

- $\quad$ The evidence does not support previous conclusions with most of the studies finding null associations between human milk TGF- $\beta$ and allergic outcomes in children. Studies lack methodological standardisation, resulting in high heterogeneity. 
- $\quad$ Future research should focus on the assessment of multiple immune markers, human milk oligosaccharides and microbiome in relationship with the allergic outcomes, as it is highly likely that a combination, rather than a single factor contributes to potential protective effect. Standardisation of methodology, statistical analysis and outcome definitions should be considered a top priority for the future research to allow for data meta-analysis.

68

69

70

71

72

73

74

75

76

77

78

79

80

81

82

83

84

85

86

87

88

89

90

91

\section{Key words}

Human milk; breast milk; colostrum; TGF- $\beta$; transforming growth factor-beta; allergic outcomes; allergic diseases; allergic sensitization; atopy; breastfeeding.

Abbreviations used

AR: allergic rhinitis

ARC: allergic rhinoconjunctivitis

AS: atopic sensitization

CI: confidence intervals

CMA: cow’s milk allergy

ELISA: enzyme-linked immunosorbent assay

E: eczema

FA: food allergy

ISAAC: international study of asthma and allergies in childhood questionnaire

MM: mature milk

NICE: national institute for clinical excellence methodological checklists

PRISMA: preferred reporting items for systematic reviews and meta-analyses guidelines

HM: human milk

HMO: human milk oligosaccharides

OR: odds ratio

slgE: specific immunoglobulin E 
92

93

94

95

96

97

98

SPT: skin prick test

TGF- $\beta$ : transforming growth factor-beta

TM: transitional milk

RR: Relative risk

\section{Introduction}

Human milk (HM) is the main source of nutrition during early life, a critical period of metabolic and immune programming. It is well known that HM consists of essential macro- and micronutrients, vitamins, antibodies and many other bioactive factors, essential for the growth and development of a newborn infant

${ }^{1}$ and for protection against infections ${ }^{2}$. However, there is conflicting evidence on the protective role of breastfeeding in relation to the development of allergic sensitization and allergic diseases ${ }^{3}$ with children bearing the greatest burden of these increasingly prevalent conditions in modern relatively affluent environments ${ }^{4}$.

Transforming growth factor-beta (TGF- $\beta$ ) is a regulatory cytokine possessing pleiotropic functions, and is involved in physiological and pathological processes including embryogenesis, immune regulation and inflammation ${ }^{5}$. Three TGF- $\beta$ isoforms (TGF- $\beta 1,2$ and 3) are present in HM with TGF- $\beta 2$ being a predominant type ${ }^{6}$. TGF- $\beta$ concentration varies considerably throughout lactation, with highest levels detected in colostrum ${ }^{7,8}$ followed by a rapid decline by 4-6 weeks of life ${ }^{9-11}$ and a continuing decline by $3^{6,12,13}$ and $6^{14}$ months postpartum. There has been an increasing interest in the role of HM TGF- $\beta$ as a key immunoregulatory factor that promotes IgA production ${ }^{6,15}$, assists with mucosal repair in the neonatal gastrointestinal tract ${ }^{16}$, acts as a co-factor helping in the generation of immune regulatory immune responses ${ }^{17}$ and influences the neonatal gut microbiome ${ }^{18}$. To date, the most comprehensive review of human studies was conducted a decade ago by Oddy and Rosales ${ }^{19}$, reporting an association between 
116 TGF- $\beta$ levels in HM and reduced risk of immunological outcomes in children in two-thirds of the studies.

117 The authors suggested that presence of HM TGF- $\beta$ may play an important role in gut immunity

118 functioning and maturation, leading to the subsequent promotion of oral tolerance, thus reducing the risk

119 of allergy development ${ }^{19}$. High heterogeneity between the studies was highlighted, with maternal atopic

120 status or dietary intervention during pregnancy and/or lactation suggested as the main reason.

121

122 Despite suggested immunological benefits, the role of TGF- $\beta$ in allergy prevention remains controversial.

123 Discrepant findings may be partially related to the differences in milk collection methodology, sample

124 storage and differences in laboratory approaches. In addition, studies employed different criteria for

125 allergic predisposition of infants, definition of outcome, method of outcome assessment, environmental 126 influence ${ }^{20}$ and ethnicity ${ }^{21}$.

127

128 The importance of the links between HM composition and allergic disease development has received 129 significant attention recently and objective assessment of existing evidence is timely. The aim of this 130 systematic review is to summarise current knowledge on associations between HM TGF- $\beta$ and 131 atopy/allergy development. 


\section{Methods}

133 This systematic review is reported in accordance with the recommendations set forth by the Preferred

134 Reporting Items for Systematic Reviews and Meta-Analyses (PRISMA) statement ${ }^{22}$. Methods were 135 published apriori (PROSPERO 2017 CRD42017069920, available from: 136 http://www.crd.york.ac.uk/PROSPERO/display_record.php?ID=CRD42017069920) on the 6th of July 137 2017).

\section{Search strategy}

139 An extensive electronic search of MEDLINE, EMBASE and Cochrane Library was performed on the $7^{\text {th }}$ 140 June 2017, using both free text and MESH terms. The search strategies are provided as supplementary material (Table S1). At a screening stage, further studies were traced through cross-checking of reference

142 lists from identified relevant papers.

143 The relationships between TGF- $\beta$ concentrations in HM (including colostrum, transitional milk, mature milk) and allergic diseases were studied. The primary outcome variables included atopic dermatitis/eczema, food allergy, asthma, allergic rhinitis, allergic conjunctivitis, allergic sensitization

146 (skin prick test (SPT) and/or specific immunoglobulin E (sIgE) measurement) and serum immunoglobulin concentrations in infants and children.

\section{Eligibility criteria and selection of articles}

149 Studies of all designs were included if the following criteria were met: 1) Reported original data; 2) 150 Clinical study of mother-infant dyads; 3) The study had an epidemiological design: observational studies, 151 i.e. pregnancy cohort study, birth cohort study, human prospective study or randomized controlled trial, during pregnancy or lactation and interventional studies; 4) Included a quantitative assessment of TGF- $\beta$ in HM; and 5) Investigated associations between HM TGF- $\beta$ and at least one allergic disease or allergic 
154 sensitization in the child. We excluded reviews, conference abstracts, editorials, letters to the editor, case 155 reports and/or case series.

157 All included papers were transferred into EndNote reference manager. To reduce potential selection bias 158 two independent investigators (EK and ZG) reviewed all titles and abstracts identified by the search for 159 inclusion. Then EK and ZG independently reviewed full texts of all publications selected for data 160 extraction. Any disagreements were resolved through discussion involving an additional reviewer (DM) and other co-authors if needed, until consensus was reached.

\section{Data extraction}

164 The data from each study were extracted in duplicate, tabulated, and included author and year of 165 publication, descriptive information concerning the study design, country and setting, baseline 166 characteristics of the study population, methodology of milk sampling, timing of sample collection, 167 method of assessment of TGF- $\beta$ concentration, outcome definition, age of outcome assessment, details on statistical analysis and overall TGF- $\beta$ association with health outcome.

\section{Quality assessment}

171 The risk of bias was assessed in duplicate (EK and ZG) using the National Institute for Clinical Excellence 172 (NICE) methodological checklist for cohort studies ${ }^{23}$ and a final score was obtained by consensus. 


\section{Results}

\section{Synthesis}

175 Based on the search strategy, a total of 353 titles were identified and 215 relevant abstracts were screened

176 for eligibility (FIG.1). Of these, 26 met the inclusion criteria and were eligible for full-text assessment

177 with 21 papers (reporting results from 20 study populations) included in our systematic review. One cohort

178 study generated 2 publications ${ }^{24,25}$ and the results were summarised according to the study population,

179 rather than by publication. Five studies were excluded as they did not assess any of the identified

180 outcomes: 1 examined the effect of probiotic administration on the risk of eczema development and

181 allergic sensitization only, without reporting the results on association with HM TGF- $\beta^{26}, 2$ studies

182 investigated TGF- $\beta$ in isolation from any allergic outcomes ${ }^{27,} 28,2$ studies assessed association between

183 TGF- $\beta$ and immunological but not allergic outcomes in infants ${ }^{14,15}$. Due to a limited number of studies

184 reporting immunological outcomes, the scope of this systematic review is limited to allergic outcomes.

185 However, as our initial search included search terms relevant for immunological outcomes, these are

186 presented in a separate subsection. 


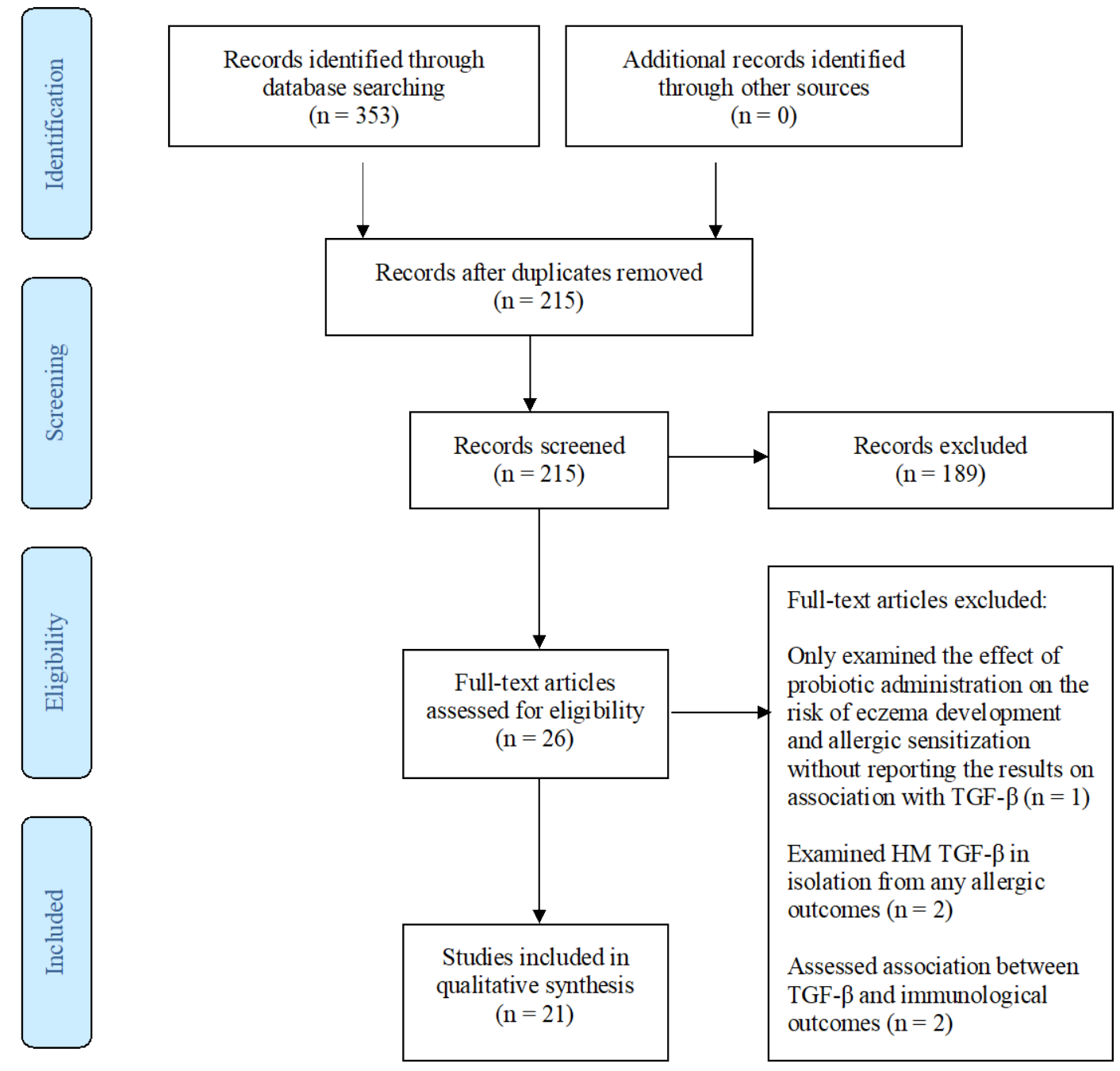

188 FIG.1 PRISMA diagram of the systematic search and included studies.

\section{Description of the studies}

190 Twenty-one studies included in this systematic review have been published between 1999 and 2017 and can be grouped into 2 main categories in accordance with the design: (a) interventional ${ }^{10-13,29-31}$ and (b)

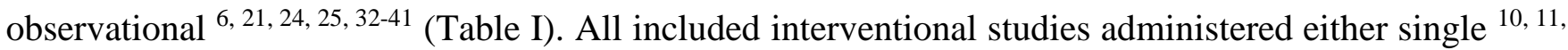
31 or multiple ${ }^{12,13,29,30}$ strains of probiotics for various durations during pregnancy ${ }^{10-13}$ and/or lactation 29-31 with exception of 1 study, which administered either formula or pasteurized HM ${ }^{39}$. However, the analyses of interventional studies were undertaken within the studies without assessing the association between intervention and allergic outcomes in children. Ten studies measured TGF- $\beta 1$ 11, 24, 25, 30, 33, 34, 36- 


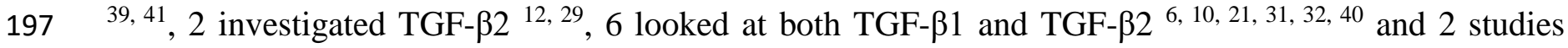
198 assessed all 3 TGF- $\beta$ isoforms ${ }^{13,35}$.

\section{$199 \quad$ Participants characteristics}

200 Study populations included participants from 15 countries, with most research conducted in Scandinavia:

2017 studies in Finland ${ }^{\text {6, 12, 29, 31, 37, 39, } 40}$ and 3 in Sweden 10, 21, 32; 3 in USA 24, 25, 34, 36; 2 in Italy ${ }^{35,38}$; and 1 in 202 Australia ${ }^{11}$, Denmark ${ }^{33}$, Estonia ${ }^{21}$, France ${ }^{37}$, Germany ${ }^{37}$, New Zealand ${ }^{30}$, Norway ${ }^{13}$, Russia ${ }^{35}$, 203 Switzerland ${ }^{37}$, The Netherlands ${ }^{41}$ and $\mathrm{UK}^{35}$.

204 Sample size ranged from $22^{38}$ to 610 participants ${ }^{37}$ while the maximum number of HM samples reached 205 $685^{12}$. Most of the studies followed children up to the age of 24 months, the maximum age of follow-up 206 was 72 months ${ }^{37}$. Thirty-five percent of cohorts (7/20) recruited participants at high risk of allergy 207 development (Table I).

\section{Stage of lactation}

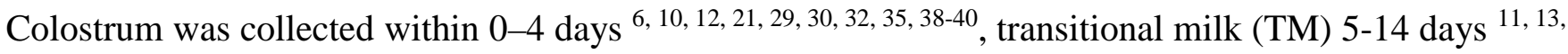

36 and mature milk (MM) between 15 days and 6 months postpartum 6, 10-13, 21, 24, 25, 30-34, 38, 41 . Eight cohorts

6, 10, 12, 21, 30, 32, 35, 38 measured TGF- $\beta$ levels in paired colostrum and MM samples. Of the remaining cohorts,

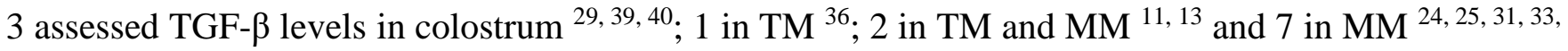
$34,36,37,41$.

\section{Methodology of human milk samples collection and storage}

The time of sample collection (time of the day, pre- or post-breastfeed) differed between the studies. Approaches to the sample collection varied with following sampling procedures reported: at the beginning of breastfeed ${ }^{12,41}$, during breastfeed (from the contra-lateral breast) ${ }^{35,41}$, at the end of breastfeed ${ }^{11} ; 2$ hours after the previous breastfeed as a full breast expression or first 2 ounces ${ }^{34}$; pooled samples from 2 
breastfeeds if milk volume was low ${ }^{12}$. Collection of the samples throughout the day also varied, with 4

studies reporting morning collections ${ }^{24,36,38,41}$ and 16 not specifying the time. In 3 cohorts HM was collected using electric breast pump ${ }^{19,24,25,41}$ while others used manual expression ${ }^{10,11,21,32,35,38}$ or collected the drip from contra-lateral breast during a breastfeeding session ${ }^{35,41}$.

Upon collection the samples were either immediately frozen ${ }^{21,32}$ or maintained at room temperature from 30 min up to $1^{24,25,30}, 4^{36,38}$ and 12 hours ${ }^{35,40}$ until transported to the laboratory, with most of the studies not fully specifying the storage/transit conditions. Identified differences in HM samples preparation

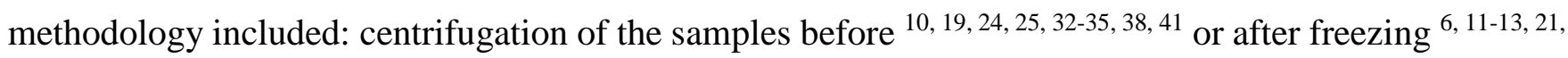
29-31, 39, 40 and differences in acid treatment of the samples.

\section{Measurement of TGF- $\beta$ in human milk}

Sixteen of 21 studies used enzyme-linked immunosorbent assay (ELISA) to quantify TGF- $\beta$ levels in HM. Other techniques included: immunoassay ${ }^{12}$, multiplex assay ${ }^{13}$, custom-made multiplex assays ${ }^{33}$, electrochemiluminescence ${ }^{35}$ and quantikine immunoassay ${ }^{40}$. There was a considerable heterogeneity in reported TGF- $\beta$ concentrations, which made quantitative synthesis (meta-analysis) not possible. Lower levels of detection for TGF- $\beta 1$ differed among the studies varying from $7 \mathrm{pg} / \mathrm{ml}^{41}$ to $30 \mathrm{pg} / \mathrm{ml}{ }^{30,36,38}$ and $60 \mathrm{pg} / \mathrm{ml}$ 21, 39 using ELISA, while detection levels for TGF- $\beta 2$ were $60 \mathrm{pg} / \mathrm{ml}$ using both ELISA ${ }^{21,39}$ and immunoassay ${ }^{12}$.

\section{Statistical analyses}

Studies included into this systematic review can be classified based on statistical methods used to address the research aim. Statistical approaches included: (a) univariate methods such as tests for groups comparison and univariate analysis of the variance (ANOVA); (b) classical multivariate regression to assess the association between risk factors and health outcome(s) adjusting for a number of confounders; 
and (c) more advanced techniques such as least absolute shrinkage and selection operator (LASSO), principal components analysis (PCA) and causal mediation. Most of the studies performed univariate analysis with 15 studies carrying out only ANOVA and/or tests for group comparison such as t-test, chisquare test, Fisher's exact test and Mann-Whitney U-test. ANOVA was performed in 6 studies to assess time effect, treatment effect and/or the interaction effect on risk factors among groups. Ten studies performed multivariate logistic regression to estimate the association between risk factors and health outcome after adjusting for potential confounding factors, whilst 3 studies used more advance methods with 2 of them reporting detailed information on sensitivity analysis (Table SII). Eighteen studies did not report sample size power calculation, and none provided information on proportion of missing values among variables and methods used to handle missing values.

Some studies reported 'trends', not supported by the statistical analysis results $(P$ - values $>0.05){ }^{10,21,29}$ and only 3 studies ${ }^{24,25,34}$ accounted for multiple comparisons. Half of the studies ${ }^{10,11,13,24,25,33-37}$ adjusted for potential confounders, including age, delivery mode, atopic status, length of breastfeeding, use of probiotics, site of collection, HM collection time, total storage time until analysis, introduction of food during the first year of life, paternal history of allergic diseases and presence of older siblings (Table SII).

\section{Allergic health outcomes measured}

Health outcomes were defined by clinical diagnosis 6 6, 10-13, 21, 29-32, 34, 38, 39, parental report $24,35,36,41$ and questionnaires with further clinical evaluation by the medical doctor $33,37,40$ or based on well-validated instruments, such as “The International Study of Asthma and Allergies in Childhood” (ISAAC) study questionnaire ${ }^{25}$, Hanifin and Rajka criteria ${ }^{10,29,33}$ and UK Working party criteria ${ }^{11-13,30}$ for eczema. A single study obtained information on eczema diagnosis using both questionnaires with further evaluation by medical doctor, while wheezing was reported by parents ${ }^{41}$. 
270 Among health outcomes measured in this review, 16 (80\%) population studies assessed the association

271 between TGF- $\beta$ concentration and risk of eczema, 9 (45\%) asthma and/or wheezing, 6 (30\%) food allergy

272 development, 3 (15\%) allergic rhinoconjunctivitis and 14 (70\%) allergic sensitisation (Tables I, SIII). 
KHALEVA \& GRIDNEVA ET AL 14

\begin{tabular}{|c|c|c|c|c|c|c|c|c|}
\hline $\begin{array}{c}\text { Reference } \\
\text { (year of publication) }\end{array}$ & $\begin{array}{c}\mathrm{N} \text { of } \\
\text { participants/ } \\
\text { milk samples }\end{array}$ & Country & Population $\wedge$ & $\begin{array}{l}\text { TGF- } \beta \text { assessed } \\
\text { and method used }\end{array}$ & $\begin{array}{l}\text { Timing of sample } \\
\text { collection }\end{array}$ & $\begin{array}{c}\text { Age at } \\
\text { outcome } \\
\text { (months) }\end{array}$ & $\begin{array}{l}\text { Health outcomes reported } \\
\text { (method of assessment) }\end{array}$ & $\begin{array}{l}\text { Overall } \\
\text { effect* }\end{array}$ \\
\hline \multicolumn{9}{|c|}{ Interventional studies } \\
\hline Rautava $2002^{31}$ & 62/NR & Finland & High risk & $\begin{array}{l}\text { TGF- } \beta 1,2 \\
\text { (ELISA) }\end{array}$ & MM (3mo) & 24 & E, CMA (clinical history, DBPC, SPT), AS (SPT) & NS \\
\hline Bottcher $2008{ }^{10}$ & 109/109 & Sweden & High risk & $\begin{array}{l}\text { TGF- } \beta 1,2 \\
\text { (ELISA) }\end{array}$ & $\begin{array}{c}\text { C (3d) } \\
\text { MM (1mo) }\end{array}$ & 24 & E (Hanifin and Rajka criteria), AS (SPT and/or sIgE) & $\dot{-}$ \\
\hline Huurre $2008{ }^{29}$ & 140/NR & Finland & High risk & $\begin{array}{l}\text { TGF- } \beta 2 \\
\text { (ELISA) }\end{array}$ & $\mathrm{C}(0 \mathrm{~d})$ & 12 & AS (SPT) & NS \\
\hline Prescott $2008^{30}$ & $105 / 105$ & New Zealand & High risk & $\begin{array}{l}\text { TGF- } \beta 1 \\
\text { (ELISA) }\end{array}$ & $\begin{array}{c}\text { C (3-7d) } \\
\operatorname{MM}(1,3 \mathrm{mo})\end{array}$ & 24 & E (UK Working party criteria), AS (SPT) & NS \\
\hline Kuitunen $2012^{12}$ & $\mathrm{NR} / 278^{\bullet}$ & Finland & High risk & $\begin{array}{c}\text { TGF- } \beta 2 \\
\text { (Immunoassay) }\end{array}$ & $\begin{array}{l}\text { C (0-3d) } \\
\text { MM (3mo) }\end{array}$ & $60^{\bullet}$ & $\begin{array}{c}\text { FA (OFC); E (UK Working party criteria); } \\
\text { A, AR (DD) }\end{array}$ & $(\mathrm{E}, \overline{\mathrm{AD}})$ \\
\hline Ismail $2013^{11}$ & 79/79 & Australia & High risk & $\begin{array}{l}\text { TGF- } \beta 1 \\
\text { (ELISA) }\end{array}$ & $\begin{array}{l}\text { TM (7d) } \\
\text { MM (28d) }\end{array}$ & 12 & $\begin{array}{c}\text { E (UK Working party criteria), AS (SPT), IgE- } \\
\text { associated E (positive SPT) }\end{array}$ & NS \\
\hline Simpson $2016^{13}$ & $259 / 259$ & Norway & Normal risk & $\begin{array}{c}\text { TGF- } \beta 1-3 \\
\text { (Multiplex assay) }\end{array}$ & $\begin{array}{l}\text { TM (10d) } \\
\text { MM (3mo) }\end{array}$ & 24 & E (UK Working party criteria), AS (SPT and/or slgE) & NS \\
\hline \multicolumn{9}{|c|}{ Observational studies } \\
\hline Kalliomaki $1999^{6}$ & $47 / 43^{\bullet}$ & Finland & Normal risk & $\begin{array}{l}\text { TGF- } \beta 1,2 \\
\text { (ELISA) }\end{array}$ & $\begin{array}{c}\text { C (0d) } \\
\text { MM (3mo) }\end{array}$ & 12 & E (Hanifin and Rajka criteria) & $\begin{array}{c}+ \\
+ \\
(\mathrm{E})\end{array}$ \\
\hline Saarinen $19999^{39}$ & $325 / \mathrm{NR}$ & Finland & Normal risk & $\begin{array}{l}\text { TGF- } \beta 1 \\
\text { (ELISA) }\end{array}$ & C (1-4d) & $3-13$ & $\begin{array}{l}\text { CMA (Typical symptoms, SPT, sIgE), AS (positive } \\
\text { SPT or sIgE) }\end{array}$ & $\stackrel{+}{+}$ \\
\hline Bottcher $2003^{32}$ & $53 / 53$ & Sweden & Normal risk & $\begin{array}{l}\text { TGF- } \beta 1,2 \\
\text { (ELISA) }\end{array}$ & $\begin{array}{l}\text { C }(0-4 \mathrm{~d}) \\
\mathrm{MM}(1 \mathrm{mo})\end{array}$ & 24 & AS (SPT); A,E,ARC (DD) • & NS \\
\hline Oddy $2003^{36}$ & $243 / 142^{\bullet}$ & USA & Normal risk & $\begin{array}{l}\text { TGF- } \beta 1 \\
\text { (ELISA) }\end{array}$ & TM (14d) & 12 & W (Parental-reported) & $\stackrel{+}{(W)}$ \\
\hline Savilahti $2005{ }^{40}$ & $228 / 227^{\bullet}$ & Finland & Normal risk & $\begin{array}{c}\text { TGF- } \beta 1,2 \\
\text { (Quantikine } \\
\text { Immunoassay) }\end{array}$ & $C(1-4 d)$ & 48 & $\begin{array}{l}\text { CMA, E, A, AR, AC (questionnaire, paediatrician } \\
\text { evaluation), AS (SPT, slgE) }\end{array}$ & NS \\
\hline Rigotti $2006{ }^{38}$ & $22 / 22$ & Italy & Normal risk & $\begin{array}{l}\text { TGF- } \beta 1 \\
\text { (ELISA) }\end{array}$ & $\begin{array}{c}\text { C (3d) } \\
\text { MM (1mo) }\end{array}$ & 6 & E (paediatrician evaluation) & NS \\
\hline Snijders $2006{ }^{41}$ & $315 / 307^{\bullet}$ & $\begin{array}{l}\text { The } \\
\text { Netherlands }\end{array}$ & Normal risk & $\begin{array}{l}\text { TGF- } \beta 1 \\
\text { (ELISA) }\end{array}$ & MM (1mo) & $24 \cdot-$ & $\begin{array}{l}\text { E (ISAAC questionnaire, UK Working party } \\
\text { criteria), W (Parental-reported), AS (sIgE) }\end{array}$ & NS \\
\hline Tomicic $2010{ }^{21}$ & 99/99 & $\begin{array}{l}\text { Estonia, } \\
\text { Sweden }\end{array}$ & Normal risk & $\begin{array}{l}\text { TGF- } \beta 1,2 \\
\text { (ELISA) }\end{array}$ & $\begin{array}{c}\text { C }(0-4 \mathrm{~d}) \\
\mathrm{MM}(1 \mathrm{mo})\end{array}$ & 24 & $\begin{array}{l}\text { AS (SPT and/or slgE); } \\
\text { E (DD) }\end{array}$ & NS \\
\hline
\end{tabular}


KHALEVA \& GRIDNEVA ET AL 15

\begin{tabular}{|c|c|c|c|c|c|c|c|c|}
\hline $\begin{array}{c}\text { Soto-Ramirez } \\
\mathbf{2 0 1 2}^{25} \\
2016^{24}\end{array}$ & $178 / 115$ & USA & Normal risk & $\begin{array}{l}\text { TGF- } \beta 1 \\
\text { (ELISA) }\end{array}$ & MM (21d) & 12 & $\begin{array}{l}\text { Scratching (questionnaires); asthma-like symptoms } \\
\text { (ISAAC questionnaire) }\end{array}$ & $\begin{array}{l}+ \\
(W)\end{array}$ \\
\hline Joseph $2014^{34}$ & $304 / 304$ & USA & Normal risk & $\begin{array}{l}\text { TGF- } \beta 1 \\
\text { (ELISA) }\end{array}$ & MM (1mo) & 36 & FA (DD), AS (SPT, slgE) & $\stackrel{+}{(\mathrm{AS})}$ \\
\hline Orivuori $2014^{37}$ & $610 / 610$ & $\begin{array}{l}\text { Finland, } \\
\text { France, } \\
\text { Germany, } \\
\text { Switzerland }\end{array}$ & Normal risk & $\begin{array}{l}\text { TGF- } \beta 1 \\
\text { (ELISA) }\end{array}$ & MM (2mo) & $72+\cdots$ & E and A (questionnaires, DD), AS (slgE) & NS \\
\hline Jepsen $2016{ }^{33}$ & $223 / 223$ & Denmark & High risk & $\begin{array}{c}\text { TGF- } \beta 1 \\
\text { (custom-made } \\
\text { Multiplex Assay) }\end{array}$ & MM (1mo) & 36 & E (Hanifin and Rajka criteria), W (daily diaries, DD) & NS \\
\hline Munblit $2017^{35}$ & $398 / 315$ & $\begin{array}{l}\text { UK, Italy, } \\
\text { Russia }\end{array}$ & Normal risk & $\begin{array}{c}\text { TGF- } \beta 1-3 \\
\text { (Electro- } \\
\text { chemiluminescence) }\end{array}$ & $\begin{array}{l}\text { C }(0-6 \mathrm{~d}) \\
\mathrm{MM}(1 \mathrm{mo})\end{array}$ & 6 & E, FA, W (Parental- reported), AS (SPT) & $\begin{array}{l}- \\
(\mathrm{E})\end{array}$ \\
\hline
\end{tabular}

Table I. Characteristics of the included studies A, asthma; AD, allergic diseases (cumulative outcome); AR, allergic rhinitis; ARC, allergic rhinoconjunctivitis; AS, allergic sensitization; C, colostrum (0-4 days) CMA, cow's milk allergy; D, days; DBPCFC, double-blind placebo-controlled food challenge; DD, doctor diagnosis; E, eczema; ELISA, enzyme-linked immunosorbent assay; FA, food allergy; ISAAC, International Study of Asthma and Allergies in Childhood; MM, mature milk (2 weeks and later); MO, months; NR, not reported; OFC, oral food challenge; SPT, skin prick test; sIgE, specific IgE levels; TGF- $\beta$, transforming growth factor-beta; TM, transitional milk (5-14 days); W, wheezing.

SPecific IgE levels; TGF- $\beta$, transforming growth factor-beta; TM, transitional milk (5-14 days); W, wheezing. 4 years. * overall effect of TGF- $\beta 1$-3: “NS” - no significant effect; “+” - protective effect, “-” - higher risk of development of any reported allergic disease and/or allergic sensitization. ^ Children at high risk of allergy development were identified based on allergic history of mothers and/or family history. ${ }^{*}$ Number of analysed milk samples for TGF- $\beta$ concentration unless not reported. $\bullet$ Some allergic outcomes were combined for the purpose of statistical analyses. 


\section{TGF- $\beta$ and development of allergic diseases}

275

Overall, $60 \%$ of study populations in the review (12/20) showed no associations with HM TGF- $\beta, 5 / 20$ (25\%) - protective effect and 3/20 (15\%) - higher risk of allergy development (Tables I and SIII; FIG.2). TGF- $\beta 1$ showed either no or some protective effect $(5 / 18,28 \%)$ on infant allergic outcomes, while conflicting results coming from TGF- $\beta 2$ studies, with 3 studies (3/10, 30\%) reporting high risk of allergy development and $1(1 / 10,10 \%)$ - protective effect of TGF- $\beta 2$ (FIG.3). TGF- $\beta 3$ showed no associations with allergy development or allergic sensitisation ${ }^{13,35}$. Five out of 15 individual health outcomes assessed at children below 2 years of age were associated with TGF- $\beta$ in HM. Out of 30 individual health outcomes assessed at 2 years of age and beyond, only 3 were associated with the levels of TGF- $\beta$ in HM (FIG.2).

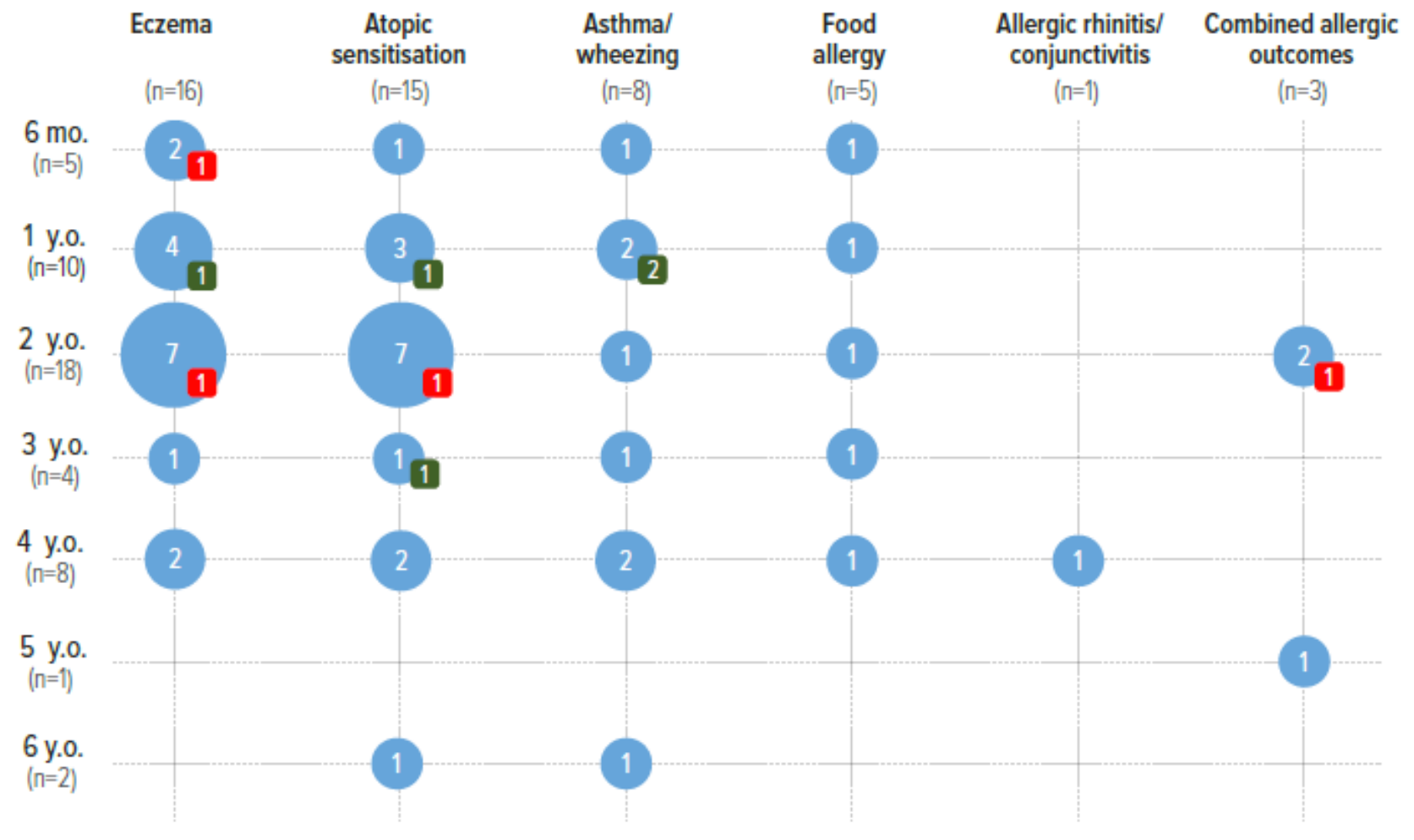

FIG.2. Matrix of associations between TGF- $\beta$ (cumulatively isoforms 1,2 and 3 ) in human milk and allergic outcomes at different age of outcome assessment. Horizontal lines indicate age of outcome assessment and vertical lines indicate allergic outcomes. Blue circle size indicates the total number of studies representing the matrix point and internal, smaller circles, indicate the number of studies showing positive (green circle)/negative (red circle) association between TGF- $\beta$ and given allergic outcome, if available. Y.O. - years old, MO. - months. 


\begin{tabular}{|c|c|c|c|c|c|}
\hline Study & Eczema & Food allergy & Asthma/wheezing & $\begin{array}{c}\text { Allergic rhinitis and/or } \\
\text { conjunctivitis }\end{array}$ & Atopic sensitization \\
\hline \multicolumn{6}{|c|}{ Interventional studies } \\
\hline \multicolumn{6}{|l|}{ Rautava et al., 2002} \\
\hline Bottcher et al., 2008 & & & & & TGF- $\beta 2$ \\
\hline \multicolumn{6}{|l|}{ Huurre et al., 2008} \\
\hline \multicolumn{6}{|l|}{ Prescott et al., 2008} \\
\hline \multicolumn{6}{|l|}{ Kuitunen et al., $2012 *$} \\
\hline \multicolumn{6}{|l|}{ Ismail et al., 2013} \\
\hline \multicolumn{6}{|l|}{ Simpson et al., 2016} \\
\hline \multicolumn{6}{|c|}{ Observational studies } \\
\hline Kalliomaki et al., 1999 & TGF- $\beta 1,2$ & & & & \\
\hline Saarinen et al., 1999 & & & & & TGF- $\beta 1$ \\
\hline \multicolumn{6}{|l|}{ Bottcher et al., $2003 *$} \\
\hline Oddy et al., 2003 & & & TGF- $\beta 1$ & & \\
\hline \multicolumn{6}{|l|}{ Savilahti et al., 2005} \\
\hline \multicolumn{6}{|l|}{ Rigotti et al., 2006} \\
\hline \multicolumn{6}{|l|}{ Snijders et al., 2006} \\
\hline \multicolumn{6}{|l|}{ Tomicic et al., 2010} \\
\hline Soto-Ramirez et al., 2012, 2016 & & & TGF- $\beta 1$ & & \\
\hline Joseph et al., 2014 & & & & & TGF- $\beta 1$ \\
\hline \multicolumn{6}{|l|}{ Orivuori et al., 2014} \\
\hline \multicolumn{6}{|l|}{ Jepsen et al., 2016} \\
\hline Munblit et al., 2017 & TGF- $\beta 2$ & & & & \\
\hline
\end{tabular}

FIG.3. Summary of associations between different isoforms of transforming growth factor beta in human milk and allergic outcomes in children. Colored boxes show significant positive (green) or negative (red) association between TGF- $\beta$ and particular allergic outcome. * Allergic outcomes in this study were combined for the purpose of statistical analyses.

\section{TGF- $\beta$ and eczema}

No consistent association was found between HM TGF- $\beta$ and development of eczema. Among 15 studies 
milk TGF- $\beta 2$ were at higher risk (OR, 1.04; 95\% CI, 1.01-1.06) of eczema development at 6 months ${ }^{35}$. Notably, Kuitunen et al. reported no association between TGF- $\beta 2$ in colostrum and eczema, but higher TGF- $\beta 2$ concentration in mature milk was associated with eczema at 2 years of life ${ }^{12}$. For TGF- $\beta 1$, Kalliomaki et al. found higher concentrations in colostrum of mothers of infants with post-weaning onset of eczema compared with those with no and pre-weaning onset of disease ${ }^{6}$.

\section{TGF- $\beta$ and food allergy}

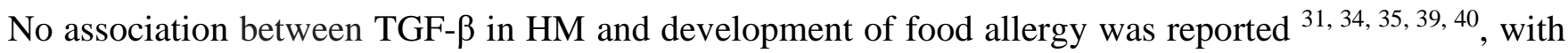
an exception of Saarinen et al. study, as authors reported concentration of TGF- $\beta 1$ in colostrum of mothers of infants with non IgE-mediated cow's milk allergy was significantly higher (mean 1162; 95\% CI 8811531) pg/ml) than in IgE-mediated cow’s milk allergy (589; 413-840) and healthy individuals (807; 677$963 \mathrm{pg} / \mathrm{ml})^{39}$.

\section{TGF- $\beta$ and allergic sensitization}

Among 20 cohorts ${ }^{10,11,13,21,29-32,34,35,37,39-41} 14$ investigated relationship between HM TGF- $\beta$ and allergic sensitization with only two reporting protective effect and one associated with high risk. Bottcher et al. found lower levels of TGF- $\beta 2(<701 \mathrm{pg} / \mathrm{ml})$ in colostrum of mothers of non-sensitized children at 24 months of age (OR, 0.3; 95\% CI, 0.1-0.9), although higher levels (>1400 pg/ml) were not associated with an increased risk of sensitization at 6 months of age (OR, 5.0; 95\% CI, 0.9-27; $P=.06)^{10}$. Saarinen et al. ${ }^{39}$ reported weak negative correlation between the concentration of colostrum TGF- $\beta 1$ and SPT diameter to cow's milk ( $r=-0.23 ; P=0.02)$, $\beta$-lactoglobulin $(r=-0.35, P=.01)$ and stimulation index to $\alpha$-casein $(r=-0.28, P=.04)$ measured in infants with cow's milk allergy at the time of the challenge. In the study of Joseph et al., among non-atopic mothers HM TGF- $\beta 1$ concentrations were lower for those infants classified as allergen-specific sIgE $(1347,1134-1600$ vs. $1651,1427-1910 \mathrm{pg} / \mathrm{ml}$ respectively, $P=.047)$ but among atopic mothers concentrations for these infants were higher (2161, 1868-2499 vs. 1525, 1347- 
325

326

327

328

329

330

331

332

333

334

335

336

337

338

339

340

341

342

343

344

345

346

347

$1726 \mathrm{pg} / \mathrm{ml}, P=.001$ ), with no significant difference in concentration when stratified by positive SPT ${ }^{34}$.

Orivuori et al. reported no consistent results at 4 and 6 years, however, at 6 years adjusted logistic regression models for IgE cut-off of $3.5 \mathrm{kU} / \mathrm{l}$, but not for 0.35 and $0.7 \mathrm{kU} / \mathrm{l}$, showed a significant difference (aOR, 95\% CI : Q1, 0.40, 0.18-0.90, $P<0.05$; Q2, 0.26, 0.11-0.61, $P<0.01)^{37}$.

\section{TGF- $\beta$ and asthma/recurrent wheezing}

Seven studies investigated associations between HM TGF- $\beta$ and either asthma ${ }^{37,40}$ or recurrent wheezing $25,33,35,36,41$. Most of the studies reported no significant findings with only 2 detecting a protective effect of TGF- $\beta 1$. In adjusted analyses, Soto-Ramirez et al. found that infants exposed to higher levels of TGF$\beta 1$ in mature HM had a lower risk of development of asthma-like symptoms at 6 and 12 months $(\mathrm{RR}=$ $0.31(0.13-0.76)$ and $0.26(P=0.01)$ respectively $)^{25}$. Similarly, Oddy et al. found a smaller percentage of wheeze in infants that received a higher dose of TGF- $\beta 1$ through transitional HM $(P=0.02)^{36}$.

\section{TGF-ß and allergic rhinitis/allergic rhinoconjunctivitis}

The association between HM TGF- $\beta$ levels and allergic rhinitis and/or allergic rhinoconjunctivitis was assessed in one cohort only, with no significant associations found ${ }^{40}$.

\section{TGF- $\beta$ and immunological outcomes}

Although our systematic review is focused on allergic outcomes, the initial search included search terms for immunological outcomes, so we provide an overview of the existing studies approaching this topic.

Ogawa et. al. studied associations between TGF- $\beta 1$ and TGF- $\beta 2$ in colostrum of healthy mothers and serum IgA in newborns during the first month of life ${ }^{15}$. Notably, an increase of serum IgA in infants from birth to 1 month of life correlated with levels of both TGF- $\beta 1(r=0.38, P=.005)$ and TGF- $\beta 2(r=0.45$, $P<0.001)$, while increase of IgM marginally correlated only with TGF- $\beta 2(\mathrm{r}=0.28, P=0.04)$ suggesting 
that colostral TGF- $\beta$ may serve as the stimulus for IgA production in newborn infants. In line with this notion, Saarinen et al. found a positive correlation between TGF- $\beta 1$ in colostrum and both, IgA antibodies to $\beta$-lactoglobulin ( $\mathrm{r}=0.204, P=0.04)$ and $\operatorname{IgG}$ antibodies to $\alpha$-casein $(\mathrm{r}=0.237, P=0.02)$ in infants prone to $\mathrm{CMA}^{39}$. Moreover, the size of SPT to CM (r = -0.228, $\left.P=0.02\right)$ was negatively associated with the level of TGF- $\beta 1$, indicating that TGF- $\beta 1$ may inhibit IgE-mediated reactions to CM. Comparatively, TGF- $\beta 2$ concentration in colostrum has been reported to associate with specific IgA responses to dietary antigens at 3 months of age $(P=0.048)^{6}$. In contrast, Prokesova et. al. investigated changes in the immune system of children genetically predisposed to allergic diseases reporting no significant differences in concentrations of TGF- $\beta$ in colostrum and mature HM of allergic mothers compared with non-allergic mothers ${ }^{14}$. Although differences in concentrations of serum cytokines (IL-4, IL-10, IFN- $\gamma$ ) between the groups of healthy and high risk infants were reported, no analysis was conducted to test for associations between concentrations of HM TGF- $\beta$ and these immunological outcomes ${ }^{14}$. The latter study, while reporting TGF- $\beta$ concentrations in mature HM beyond the first month of lactation, did not differentiate between TGF- $\beta$ isoforms. Difference in methodology, study design and immunological outcomes assessed does not allow for an appropriate analysis of these data.

\section{Risk of bias}

All the studies included in this systematic review were evaluated for their quality, with most being of a medium quality (FIG.3). High risk of bias was detected in 15 studies (71\%). The main issues identified were attrition, selection and detection bias, including lack of adjustment for potential confounders and the use of self-reported questionnaires as a tool for allergic outcomes assessment.

It is worth noting that asthma diagnosis at the age below 3 years was considered an unreliable outcome as most children with "early wheeze" do not develop subsequent asthma ${ }^{42}$. We also considered any allergic outcome based on non-validated questionnaires without following clinical examination by doctor as a high risk of bias. We acknowledged any adjustments for known confounders performed by the authors, 
373 but there is no clear guidance which adjustments are imperative. Attrition bias was calculated for all 374 participants as it is not always clear if the same participants provided samples and completed the follow 375 up; high attrition bias was considered as $\leq 75 \%$. 


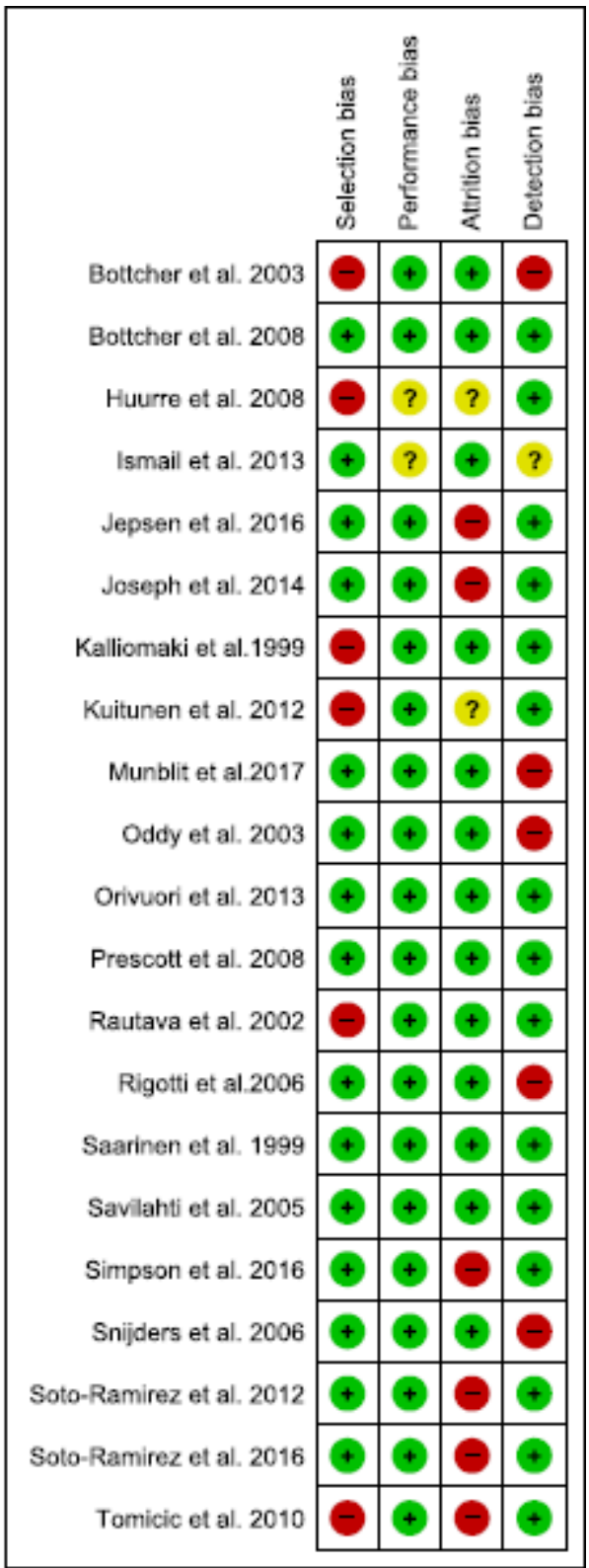

377 Fig.3 Risk of bias in studies assessing association between TGF- $\beta$ concentration in human milk and allergic outcomes using the National Institute for Clinical Excellence methodological checklist. '+, green', low risk of bias; '-, red', high risk of bias; '?, yellow', unclear risk of bias. 
380

381

382

383

384

385

386

387

388

389

390

391

392

393

394

395

396

397

398

399

400

401

402

\section{Discussion}

In this systematic review, we summarised findings of 21 studies from 20 cohorts of associations between HM TGF- $\beta$ and allergic outcomes in infancy and childhood. Data from included studies showed no strong association between any isoform of TGF- $\beta$ in HM and atopy/allergy development. Twelve new studies were identified ${ }^{10-13,21,24,25,29,33-35,37}$ since the last systematic review ${ }^{19}$, but evidence remains limited, due to high heterogeneity between studies, which makes any quantitative synthesis impossible. We used robust methods to search and synthesize evidence, provided critical analysis, identified several key strengths and limitations in the current literature and highlighted the unmet needs. In this paper, we provide a comprehensive overview of relationships between the levels of TGF- $\beta$ in HM and allergic outcomes.

Although it was not possible to perform a meta-analysis, qualitative synthesis suggests that there is insufficient evidence of TGF- $\beta$ influence on atopy/allergy development. Out of 15 studies only 3 found significant associations between TGF- $\beta$ and eczema, 3 out of 14 with allergic sensitisation, 2 out of 9 with wheezing/asthma and none out of 5 linked TGF- $\beta$ with IgE-mediated food allergy development. These results, however, do not completely exclude the possibility of TGF- $\beta$ to impact allergic diseases development as a protective or negative effect was reported in some studies, with TGF- $\beta 1$ being predominantly related to a protective effect and TGF- $\beta 2$ associating with a higher risk of allergic disease. Studies differed in methods applied and outcomes reported and in addition to methodological heterogeneity, most of the studies carried a high risk of bias, thus results should be interpreted with caution.

Across a limited number of studies suggesting associations between the levels of HM TGF- $\beta$ and allergic outcomes, opposite effects are generally reported for TGF- $\beta 1$ and TGF- $\beta 2$ isoforms. TGF- $\beta 1$ is mainly associated with the protective effect, while TGF- $\beta 2$ is linked with a higher risk of atopy/allergy development. There is increasingly more evidence, suggesting that TGF- $\beta$ acts as a bi-functional 
403

404

405

406

407

408

409

410

411

412

413

414

415

416

417

418

419

420

421

422

423

424

425

426

regulator, with its context-dependent nature of activities confirmed in a variety of biological responses and cell systems ${ }^{43}$. All TGF- $\beta$ isoforms share a characteristic structure and are highly pleiotropic, but each isoform is linked with specific functions, therefore, may exert different effects. While TGF- $\beta 2$ presents in much higher concentrations, accounting for up to 95\% of TGF- $\beta$ in HM, it is less potent than TGF- $\beta 1{ }^{44-46}$. TGF- $\beta 1$-deficient mice were linked with the neonatal inflammatory disease ${ }^{47}$, whereas TGF- $\beta 2$,3-deficient mice present with developmental defects ${ }^{48,49}$. This indicates that HM TGF- $\beta$ isoforms may indeed have differential effects on allergy development.

HM contains a plethora of immune moderators ${ }^{50}$, which may have synergistic and/or antagonistic effects to TGF- $\beta$, thus subsequently influencing the risk of atopy/allergy development. A recent study has investigated the effect of the immunological milieu of HM including 28 cytokines, chemokines and growth factors on development of cow's milk allergy. The authors reported interactions between the immune markers and showed that networks of HM regulatory and pro-inflammatory cytokines including TGF- $\beta 1$, IL-1 $\beta$, IL-6 and IL-10 are associated with tolerance to cow's milk development ${ }^{51}$. These findings suggest that narrowing research to single components could result in conflicting and even misleading findings and suggests that HM studies should implement a more holistic approach given the links between development of the immune system and both the gut microbiome ${ }^{52}$ and HM oligosaccharides (HMO) ${ }^{53}$.

We found a high degree of heterogeneity between studies, with differences in methodology (sample collection, storage and processing), populations (general population and high risk), outcome definition, age at outcome assessment, and approaches to statistical analysis being the most important contributors. Lack of standardized protocols of HM sample collection, storage and processing is an important issue, influencing the quality of $\mathrm{HM}$ research ${ }^{54}$, associated with heterogeneity and not allowing for quantitative synthesis. 
428 Previous research linked a number of physiological and environmental factors with the changes of TGF$429 \beta$ levels in HM. Stage of lactation and time of sample collection ${ }^{9}$, circadian and seasonal variations ${ }^{55,56}$, 430 time prior to freezing and length of sample storage ${ }^{57}$, differences in laboratory techniques ${ }^{55}$, ethnicity ${ }^{34}$, 431 residency ${ }^{21}$, maternal lifestyle ${ }^{35}$, smoking ${ }^{37}$, diet ${ }^{58}$, infection ${ }^{59}$ as well as depression and anxiety ${ }^{56,60}$ 432 were found to be a confounders and appear to impact TGF- $\beta$ concentrations, thus possibly impacting 433 health outcome development. Very few studies collected sufficient information and accounted for the duration and exclusivity of breastfeeding. Absence of this information prevents in-depth analysis of the dose-dependent effect. Although examination of associations between colostrum concentrations of HM components and infant outcomes is usually straightforward, the investigation of relationships with concentrations in mature HM is more problematic, given the variability in breastfeeding patterns and volumes of HM consumed during the lactation ${ }^{61}$. Our systematic review highlights pitfalls in HM research, with results not being data adjusted for known confounding factors in many studies up to date with only a few using multivariate statistical analysis (Table SII).

Differences in statistical methods applied largely contributed to the results of this review, with a large variety of strategies employed, yet lacking comprehensive approach and consistency. The issues associated with carrying out multiple hypothesis tests were rarely considered leading to a high risk of false-positive results and missing data was common but not dealt with, possibly resulting in under- and/or over-estimation of association between the exposure and outcome ${ }^{62}$. Adjustment for potentially important confounding factors may play an important part in identifying associations between levels of TGF- $\beta$ and infant allergic outcomes but 6 studies did not report any adjustment. With heterogeneity in sample collection and processing, another important factor making meta-analysis impossible was data reporting, 
451

452

453

454

455

456

457

458

459

460

461

462

463

464

465

466

467

468

469

470

471

472

473

474

particularly if associations were not found to be significant. The different designs of the studies, e.g. observational and interventional, make it difficult to compare the results, as potential influence of the intervention cannot be excluded.

Health outcome definitions significantly varied between the studies contributing to heterogeneity. Some studies used less reliable measurements such as infant itchy rash ${ }^{35}$, scratching ${ }^{24}$ or asthma-like symptoms ${ }^{25}$. Parental-reported allergic outcomes are not always accurate and the possibility of overdiagnosis cannot be ruled out. It has been previously shown that mothers tend to over-report eczema in their children ${ }^{63}$. It should be noted, however, that most of the studies verified parental reports by physician assessment or used well-validated tools, such as the ISAAC questionnaire ${ }^{64}$ or eczema UK Working party criteria ${ }^{65}$. There is also a marked difference in the age of health outcome assessment across the studies, ranging between 6 months and 6 years of age. Thirty percent of individual health outcomes assessed in children below 2 years of age were associated with TGF- $\beta$ in HM, while only 3 out of 30 health outcomes at 2 years of age and beyond were found to be linked with TGF- $\beta$ levels. This makes impact of HM TGF- $\beta$ on allergic outcomes improbable and even if it exists in selected populations, it is highly unlikely that it extends beyond 2 years of age.

Atopic march theory suggests that allergic diseases progress from inflammatory skin manifestations, such as eczema during infancy, to asthma and allergic rhinitis in later childhood ${ }^{66}$. It has been demonstrated that many "early wheezers" do not subsequently develop persistent asthma ${ }^{42}$. There may even be an inverse relationship between early infection-induced wheeze and subsequent asthma ${ }^{67}$. It should be noted that most of the studies assessing asthma included in this systematic review, were realistically measuring wheeze rather than asthma, as age at health outcome assessment does not allow for appropriate asthma diagnosis. Apart from the Orivuori et al. diagnosing asthma at 6 years of life ${ }^{37}$, no other study measured 
475 this health outcome beyond the age of 4 years. Considering lack of studies reporting doctor's diagnosed

476 health outcomes there is a need in further prospective cohorts, using well-validated instruments and 477 standardized definitions, assessments of allergic outcomes and a considerable follow-up to evaluate the 478 persistency of allergic symptoms.

The most recent systematic review ${ }^{19}$ provided an overall measure of the effect of HM TGF- $\beta$ on immunological outcomes in infants and children and reported that 8 out of 12 studies showed a positive association between either TGF- $\beta 1$ or TGF- $\beta 2$ concentrations and a reduction in allergy-related outcomes. These results are in conflict with our findings, which may be explained by the difference in systematic review inclusion criteria. Oddy and Rosales reviewed all the studies reporting any immunological, biochemical and/or clinical outcomes, including those assessing associations between maternal allergic status and HM TGF- $\beta$ concentration, while this paper reviews associations between HM TGF- $\beta$ and atopy/allergy development in offspring only.

\section{Conclusion}

TGF- $\beta$ is an important immunological factor involved in inflammation regulation. Biological effects of HM TGF- $\beta$ on allergic outcomes during infancy and childhood need to be further elucidated. Although several associations have been observed between HM TGF- $\beta$ and allergic outcomes, our updated systematic review did not find strong evidence of association between the levels of TGF- $\beta$ in HM and atopy/allergy development. Studies would benefit from an investigation into any dose-dependent effect, with an apparent lack of studies measuring exact amounts of breast milk consumed, in addition to immuno-active molecules measurement. Future studies should employ standardised, validated methods, 
497

498

499

\section{Acknowledgements}

501

502

503

504

505

506

507

508

509

510

511

512

513

514

515

516

517

518

519

520

521

522

523

524

525

526

527

528

529

530

531

532

533

534

535

\section{References}

meta-analyses. Implementation of a more holistic approach, assessing multiple immune markers level, HMO and microbiome would improve the quality of the research in the field.

All authors critically reviewed and approved the final manuscript.

1. Hanson LA, Korotkova M, Lundin S, Haversen L, Silfverdal SA, Mattsby-Baltzer I, et al. The transfer of immunity from mother to child. Ann N Y Acad Sci 2003; 987:199-206.

2. Labbok MH, Clark D, Goldman AS. Breastfeeding: maintaining an irreplaceable immunological resource. Nat Rev Immunol 2004; 4:565-72.

3. Munblit D, Peroni DG, Boix-Amoros A, Hsu PS, Van't Land B, Gay MCL, et al. Human Milk and Allergic Diseases: An Unsolved Puzzle. Nutrients 2017; 9.

4. Mallol J, Crane J, von Mutius E, Odhiambo J, Keil U, Stewart A. The International Study of Asthma and Allergies in Childhood (ISAAC) Phase Three: a global synthesis. Allergol Immunopathol (Madr) 2013; 41:73-85.

5. $\quad$ Cerutti A, Zan H, Schaffer A, Bergsagel L, Harindranath N, Max EE, et al. CD40 ligand and appropriate cytokines induce switching to IgG, IgA, and IgE and coordinated germinal center and plasmacytoid phenotypic differentiation in a human monoclonal IgM+IgD+ B cell line. J Immunol 1998; 160:2145-57.

6. Kalliomaki M, Ouwehand A, Arvilommi H, Kero P, Isolauri E. Transforming growth factor-beta in breast milk: a potential regulator of atopic disease at an early age. Journal of Allergy \& Clinical Immunology 1999; 104:1251-7.

7. Bottcher M. Cytokines and chemokines in breast milk from allergic and nonallergic mothers. Allergy and Clinical Immunology International 2000; 12:153-60.

8. Hawkes JS, Bryan DL, James MJ, Gibson RA. Cytokines (IL-1beta, IL-6, TNF-alpha, TGFbeta1, and TGF-beta2) and prostaglandin E2 in human milk during the first three months postpartum. Pediatr Res 1999; 46:194-9.

9. Munblit D, Treneva M, Peroni DG, Colicino S, Chow L, Dissanayeke S, et al. Colostrum and Mature Human Milk of Women from London, Moscow, and Verona: Determinants of Immune Composition. Nutrients 2016; 8.

10. Bottcher MF, Abrahamsson TR, Fredriksson M, Jakobsson T, Bjorksten B. Low breast milk TGF-beta2 is induced by Lactobacillus reuteri supplementation and associates with reduced risk of sensitization during infancy. Pediatric Allergy and Immunology 2008; 19:497-504.

11. Ismail IH, Licciardi PV, Oppedisano F, Boyle RJ, Tang MLK. Relationship between breast milk sCD14, TGF-beta1 and total IgA in the first month and development of eczema during infancy. Pediatric Allergy and Immunology 2013; 24:352-60.

12. Kuitunen M, Kukkonen AK, Savilahti E. Impact of maternal allergy and use of probiotics during pregnancy on breast milk cytokines and food antibodies and development of allergy in children until 5 years. International Archives of Allergy and Immunology 2012; 159:162-70. 
13. Simpson MR, Ro ADB, Grimstad O, Johnsen R, Storro O, Oien T. Atopic dermatitis prevention in children following maternal probiotic supplementation does not appear to be mediated by breast milk TSLP or TGF-beta. Clinical and Translational Allergy 2016; 6 (1) (no pagination).

14. Prokesova L, Lodinova-Zadnikova R, Zizka J, Kocourkova I, Novotna O, Petraskova P, et al. Cytokine levels in healthy and allergic mothers and their children during the first year of life. Pediatric Allergy and Immunology 2006; 17:175-83.

15. Ogawa J, Sasahara A, Yoshida T, Sira MM, Futatani T, Kanegane H, et al. Role of transforming growth factor-beta in breast milk for initiation of IgA production in newborn infants. Early Human Development 2004; 77:67-75.

16. Rautava S, Nanthakumar NN, Dubert-Ferrandon A, Lu L, Rautava J, Walker WA. Breast milktransforming growth factor-beta(2) specifically attenuates IL-1beta-induced inflammatory responses in the immature human intestine via an SMAD6- and ERK-dependent mechanism. Neonatology 2011; 99:192-201.

17. Ando T, Hatsushika K, Wako M, Ohba T, Koyama K, Ohnuma Y, et al. Orally administered TGF-beta is biologically active in the intestinal mucosa and enhances oral tolerance. J Allergy Clin Immunol 2007; 120:916-23.

18. Sitarik AR, Bobbitt KR, Havstad SL, Fujimura KE, Levin AM, Zoratti EM, et al. Breast Milk Transforming Growth Factor beta Is Associated With Neonatal Gut Microbial Composition. J Pediatr Gastroenterol Nutr 2017; 65:e60-e7.

19. Oddy WH, Rosales F. A systematic review of the importance of milk TGF-beta on immunological outcomes in the infant and young child. Pediatric Allergy \& Immunology 2010; 21:47-59.

20. Peroni DG, Pescollderungg L, Piacentini GL, Rigotti E, Maselli M, Watschinger K, et al. Immune regulatory cytokines in the milk of lactating women from farming and urban environments. Pediatric Allergy \& Immunology 2010; 21:977-82.

21. Tomicic S, Johansson G, Voor T, Bjorksten B, Bottcher MF, Jenmalm MC. Breast milk cytokine and IgA composition differ in Estonian and Swedish mothers-relationship to microbial pressure and infant allergy. Pediatric Research 2010; 68:330-4.

22. Moher D, Shamseer L, Clarke M, Ghersi D, Liberati A, Petticrew M, et al. Preferred reporting items for systematic review and meta-analysis protocols (PRISMA-P) 2015 statement. Syst Rev 2015; 4:1.

23. National Institute for Clinical Excellence methodological checklists for observational studies. 2013.] Available from https://www.nice.org.uk/.

24. Soto-Ramirez N, Boyd K, Zhang H, Gangur V, Goetzl L, Karmaus W. Maternal serum but not breast milk IL-5, IL-6, and IL-13 immune markers are associated with scratching among infants. Allergy, Asthma, \& Clinical Immunology : Official Journal of the Canadian Society of Allergy \& Clinical Immunology 2016; 12:25.

25. Soto-Ramirez N, Karmaus W, Yousefi M, Zhang H, Liu J, Gangur V. Maternal immune markers in serum during gestation and in breast milk and the risk of asthma-like symptoms at ages 6 and 12 months: a longitudinal study. Allergy, Asthma, \& Clinical Immunology : Official Journal of the Canadian Society of Allergy \& Clinical Immunology 2012; 8:11.

26. Boyle RJ, Ismail IH, Kivivuori S, Licciardi PV, Robins-Browne RM, Mah LJ, et al. Lactobacillus GG treatment during pregnancy for the prevention of eczema: A randomized controlled trial. Allergy: European Journal of Allergy and Clinical Immunology 2011; 66:50916.

27. Baldassarre ME, Di Mauro A, Mastromarino P, Fanelli M, Martinelli D, Urbano F, et al. Administration of a Multi-Strain Probiotic Product to Women in the Perinatal Period Differentially Affects the Breast Milk Cytokine Profile and May Have Beneficial Effects on 
Neonatal Gastrointestinal Functional Symptoms. A Randomized Clinical Trial. Nutrients 2016; 8:27.

28. Zizka J, Kverka M, Novotna O, Stankova I, Lodinova-Zadnikova R, Kocourkova I, et al. Perinatal period cytokines related to increased risk of future allergy development. Folia Microbiologica 2007; 52:549-55.

29. Huurre A, Laitinen K, Rautava S, Korkeamaki M, Isolauri E. Impact of maternal atopy and probiotic supplementation during pregnancy on infant sensitization: a double-blind placebocontrolled study. Clinical \& Experimental Allergy 2008; 38:1342-8.

30. Prescott SL, Wickens K, Westcott L, Jung W, Currie H, Black PN, et al. Supplementation with Lactobacillus rhamnosus or Bifidobacterium lactis probiotics in pregnancy increases cord blood interferon-gamma and breast milk transforming growth factor-beta and immunoglobin A detection. Clinical and Experimental Allergy 2008; 38:1606-14.

31. Rautava S, Kalliomaki M, Isolauri E. Probiotics during pregnancy and breast-feeding might confer immunomodulatory protection against atopic disease in the infant. Journal of Allergy and Clinical Immunology 2002; 109:119-21.

32. Bottcher MF, Jenmalm MC, Bjorksten B. Cytokine, chemokine and secretory IgA levels in human milk in relation to atopic disease and IgA production in infants. Pediatr Allergy Immunol 2003; 14:35-41.

33. Jepsen AA, Chawes BL, Carson CG, Schoos AMM, Thysen AH, Waage J, et al. High breast milk IL-1beta level is associated with reduced risk of childhood eczema. Clinical and Experimental Allergy 2016; 46:1344-54.

34. Joseph CL, Havstad S, Bobbitt K, Woodcroft K, Zoratti EM, Nageotte C, et al. Transforming growth factor beta (TGFbeta1) in breast milk and indicators of infant atopy in a birth cohort. Pediatric Allergy \& Immunology 2014; 25:257-63.

35. Munblit D, Treneva M, Peroni DG, Colicino S, Chow LY, Dissanayeke S, et al. Immune Components in Human Milk Are Associated with Early Infant Immunological Health Outcomes: A Prospective Three-Country Analysis. Nutrients 2017; 9:24.

36. Oddy WH, Halonen M, Martinez FD, Lohman IC, Stern DA, Kurzius-Spencer M, et al. TGFbeta in human milk is associated with wheeze in infancy. Journal of Allergy and Clinical Immunology 2003; 112:723-8.

37. Orivuori L, Loss G, Roduit C, Dalphin JC, Depner M, Genuneit J, et al. Soluble immunoglobulin A in breast milk is inversely associated with atopic dermatitis at early age: the PASTURE cohort study. Clinical \& Experimental Allergy 2014; 44:102-12.

38. Rigotti E, Piacentini GL, Ress M, Pigozzi R, Boner AL, Peroni DG. Transforming growth factor-beta and interleukin-10 in breast milk and development of atopic diseases in infants. Clinical \& Experimental Allergy 2006; 36:614-8.

39. Saarinen KM, Vaarala O, Klemetti P, Savilahti E. Transforming growth factor-beta1 in mothers' colostrum and immune responses to cows' milk proteins in infants with cows' milk allergy. Journal of Allergy and Clinical Immunology 1999; 104:1093-8.

40. Savilahti E, Siltanen M, Kajosaari M, Vaarala O, Saarinen KM. IgA antibodies, TGF-beta1 and beta2, and soluble CD14 in the colostrum and development of atopy by age 4. Pediatric research 2005; 58:1300-5.

41. Snijders BEP, Damoiseaux JGMC, Penders J, Kummeling I, Stelma FF, Van Ree R, et al. Cytokines and soluble CD14 in breast milk in relation with atopic manifestations in mother and infant (KOALA Study). Clinical and Experimental Allergy 2006; 36:1609-15.

42. Wright AL. Epidemiology of asthma and recurrent wheeze in childhood. Clin Rev Allergy Immunol 2002; 22:33-44. 
43. Morikawa M, Derynck R, Miyazono K. TGF-beta and the TGF-beta Family: Context-Dependent Roles in Cell and Tissue Physiology. Cold Spring Harb Perspect Biol 2016; 8.

44. Baardsnes J, Hinck CS, Hinck AP, O'Connor-McCourt MD. TbetaR-II discriminates the highand low-affinity TGF-beta isoforms via two hydrogen-bonded ion pairs. Biochemistry 2009; 48:2146-55.

45. Cheifetz S, Hernandez H, Laiho M, ten Dijke P, Iwata KK, Massague J. Distinct transforming growth factor-beta (TGF-beta) receptor subsets as determinants of cellular responsiveness to three TGF-beta isoforms. J Biol Chem 1990; 265:20533-8.

46. Qian SW, Burmester JK, Merwin JR, Madri JA, Sporn MB, Roberts AB. Identification of a structural domain that distinguishes the actions of the type 1 and 2 isoforms of transforming growth factor beta on endothelial cells. Proc Natl Acad Sci U S A 1992; 89:6290-4.

47. Shull MM, Ormsby I, Kier AB, Pawlowski S, Diebold RJ, Yin M, et al. Targeted disruption of the mouse transforming growth factor-beta 1 gene results in multifocal inflammatory disease. Nature 1992; 359:693-9.

48. Kaartinen V, Voncken JW, Shuler C, Warburton D, Bu D, Heisterkamp N, et al. Abnormal lung development and cleft palate in mice lacking TGF-beta 3 indicates defects of epithelialmesenchymal interaction. Nat Genet 1995; 11:415-21.

49. Sanford LP, Ormsby I, Gittenberger-de Groot AC, Sariola H, Friedman R, Boivin GP, et al. TGFbeta2 knockout mice have multiple developmental defects that are non-overlapping with other TGFbeta knockout phenotypes. Development 1997; 124:2659-70.

50. D'Alessandro A, Scaloni A, Zolla L. Human milk proteins: an interactomics and updated functional overview. J Proteome Res 2010; 9:3339-73.

51. Jarvinen KM, Suarez-Farinas M, Savilahti E, Sampson HA, Berin MC. Immune factors in breast milk related to infant milk allergy are independent of maternal atopy. J Allergy Clin Immunol 2015; 135:1390-3 e1-6.

52. Tanaka M, Nakayama J. Development of the gut microbiota in infancy and its impact on health in later life. Allergol Int 2017; 66:515-22.

53. Triantis V, Bode L, van Neerven RJJ. Immunological Effects of Human Milk Oligosaccharides. Front Pediatr 2018; 6:190.

54. Fields DA, Schneider CR, Pavela G. A narrative review of the associations between six bioactive components in breast milk and infant adiposity. Obesity (Silver Spring) 2016; 24:1213-21.

55. Agarwal S, Karmaus W, Davis S, Gangur V. Immune markers in breast milk and fetal and maternal body fluids: a systematic review of perinatal concentrations. J Hum Lact 2011; 27:17186.

56. Kondo N, Suda Y, Nakao A, Oh-Oka K, Suzuki K, Ishimaru K, et al. Maternal psychosocial factors determining the concentrations of transforming growth factor-beta in breast milk. Pediatr Allergy Immunol 2011; 22:853-61.

57. Ramirez-Santana C, Perez-Cano FJ, Audi C, Castell M, Moretones MG, Lopez-Sabater MC, et al. Effects of cooling and freezing storage on the stability of bioactive factors in human colostrum. J Dairy Sci 2012; 95:2319-25.

58. Hawkes JS, Bryan DL, Neumann MA, Makrides M, Gibson RA. Transforming growth factor beta in human milk does not change in response to modest intakes of docosahexaenoic acid. Lipids 2001; 36:1179-81.

59. Chockalingam A, Paape MJ, Bannerman DD. Increased milk levels of transforming growth factor-alpha, beta1, and beta2 during Escherichia coli-induced mastitis. J Dairy Sci 2005; 88:1986-93. 
677 60. Shariat M, Abedinia N, Rezaei N, Farrokhzad N. Increase Concentration of Transforming

678

679

680

681

682

683

684

685

686

687

688

689

690

691

692

693

694

695

696

697
Growth Factor Beta (TGF-beta) in Breast Milk of Mothers With Psychological Disorders. Acta Med Iran 2017; 55:429-36.

61. Kent JC, Mitoulas LR, Cregan MD, Ramsay DT, Doherty DA, Hartmann PE. Volume and frequency of breastfeedings and fat content of breast milk throughout the day. Pediatrics 2006; 117:e387-95.

62. Kristman V, Manno M, Cote P. Loss to follow-up in cohort studies: how much is too much? Eur J Epidemiol 2004; 19:751-60.

63. Silverberg JI, Patel N, Immaneni S, Rusniak B, Silverberg NB, Debashis R, et al. Assessment of atopic dermatitis using self-report and caregiver report: a multicentre validation study. $\mathrm{Br} \mathrm{J}$ Dermatol 2015; 173:1400-4.

64. Pols DH, Wartna JB, van Alphen EI, Moed H, Rasenberg N, Bindels PJ, et al. Interrelationships between Atopic Disorders in Children: A Meta-Analysis Based on ISAAC Questionnaires. PLoS One 2015; 10:e0131869.

65. Williams HC, Burney PG, Pembroke AC, Hay RJ. The U.K. Working Party's Diagnostic Criteria for Atopic Dermatitis. III. Independent hospital validation. Br J Dermatol 1994; 131:406-16.

66. Bantz SK, Zhu Z, Zheng T. The Atopic March: Progression from Atopic Dermatitis to Allergic Rhinitis and Asthma. J Clin Cell Immunol 2014; 5.

67. de Benedictis FM, Bush A. Infantile wheeze: rethinking dogma. Arch Dis Child 2017; 102:3715 . 
698

699

700

701

702

703

704

705

706

707

708

709

710

711

712

713

714

715

716

717

TABLE S1. Search strategies.

\section{Embase Classic+Embase $<1947$ to 2017 June 7> (via Ovid)}

1 allergy/ or hypersensitivity/ or immunoglobulin/ or immunoglobulin a/ or immunoglobulin a1/ or immunoglobulin a2/ or immunoglobulin e/ or secretory immunoglobulin/

2 (allergy or allergic diseases or allerg* or immun* outcomes or eczema or atopic dermatitis or itchy rash or allergic rhinitis or hay fever or food allergy or food hypersensitivity or asthma or wheeze or respiratory hypersensitivity or eosinophilic esophagitis or Ig serum level or immunoglobin blood level or immunoglobulin level or immunoglobulin serum level or plasma immunoglobulin or serum gammaglobulin or serum immune globulin or IgA or IgA1 or IgA2 or immunoglobulin A or IgE or immunoglobulin E or secretory immunoglobulin).mp. [mp=title, abstract, heading word, drug trade name, original title, device manufacturer, drug manufacturer, device trade name, keyword, floating subheading word]

3 food allergy/ or hypersensitivity/

4 asthma/ or allergic asthma/

5 wheezing/

6 eczema/ or dermatitis/

71 or 2 or 3 or 4 or 5 or 6

8 transforming growth factor/ or transforming growth factor beta/

9 (Transforming growth factor beta or transforming growth factor beta1 or transforming growth factor beta2 or transforming growth factor beta3 or TGF beta or TGFbeta or TGF-beta or TGF*).mp. [mp=title, abstract, heading word, drug trade name, original title, device manufacturer, drug manufacturer, device trade name, keyword, floating subheading word]

\section{8 or 9}

11 colostrum/

12 human milk.mp. or breast milk/

13 (breast milk or breast milks or human milk or milk or breast milk human or mature milk or colostrum or early milk or transitional milk).mp. [mp=title, abstract, heading word, drug trade name, original title, device manufacturer, drug manufacturer, device trade name, keyword, floating subheading word]

\section{1 or 12 or 13}

15 (child* or infant* or boy* or girl* or newborn*).mp. [mp=title, abstract, heading word, drug trade name, original title, device manufacturer, drug manufacturer, device trade name, keyword, floating subheading word] (3306386) 
730

731

732

733

734

735

736

737

738

739

740

741

742

743

744

745

746

747

748

749

750

751

752

753

754

755

756

757

758

759

760

761

762

763

764

765

16 child/

17 infant/

18 newborn/

1915 or 16 or 17 or 18

$20 \quad 7$ and 10 and 14 and 19

\section{Cochrane library}

1. "allergy" or allergic diseases or allerg* or immun* outcomes or "eczema" or "atopic dermatitis" or itchy rash or "allergic rhinitis" or "hay fever" or "food allergy” or food hypersensitivity or "asthma” or "wheeze" or respiratory hypersensitivity or eosinophilic esophagitis or Ig serum level or immunoglobin blood level or "immunoglobulin" or immunoglobulin level or immunoglobulin serum level or plasma immunoglobulin or serum gammaglobulin or serum immune globulin or "IgA" or IgA1 or IgA2 or “immunoglobulin A" or "IgE” or “immunoglobulin E”

2. "Transforming growth factor beta" or "transforming growth factor beta 1" or "transforming growth factor beta 1 level" or "transforming growth factor beta1" or "transforming growth factor beta 2" or "transforming growth factor beta 3" or TGF beta or TGFbeta or TGF-beta or TGF*

3. "breast milk" or breast milks or human milk or milk or breast milk human or colostrum* or "colostrum" or mature milk or transitional milk

4. child* or "child" or infant* or "infant” or boy* or girl* or newborn* or "newborn"

5. \#1 and \#2 and \#3 and \#4

\section{Ovid MEDLINE(R) Epub Ahead of Print, In-Process \& Other Non-Indexed Citations, Ovid MEDLINE(R) Daily and Ovid MEDLINE(R) $<1946$ to Present $>$}

1 hypersensitivity/ or conjunctivitis, allergic/ or dermatitis, atopic/ or eosinophilic esophagitis/ or food hypersensitivity/ or respiratory hypersensitivity/ or asthma/ or rhinitis, allergic/ or urticaria/ or immunoglobulins/ or serum globulins/ or Immunoglobulin E/ or blood immunoglobulins.mp. or immunoglobulin a.mp. or Immunoglobulin A/

2 (allergy or allergic diseases or allerg* or immun* outcomes or eczema or atopic dermatitis or itchy rash or allergic rhinitis or hay fever or food allergy or food hypersensitivity or asthma or wheeze or respiratory hypersensitivity or eosinophilic esophagitis or Ig serum level or immunoglobin blood level or immunoglobulin level or immunoglobulin serum level or plasma immunoglobulin or serum gammaglobulin or serum immune globulin or IgA or IgA1 or IgA2 or immunoglobulin A or IgE or immunoglobulin E).mp. [mp=title, abstract, original title, name of substance word, subject heading word, keyword heading word, protocol supplementary concept word, rare disease supplementary concept word, unique identifier, synonyms]

31 or 2 
7664 transforming growth factor beta/ or transforming growth factor beta1/ or transforming growth factor 767 beta2/ or transforming growth factor beta3/

7685 (Transforming growth factor beta or transforming growth factor beta1 or transforming growth factor 769 beta2 or transforming growth factor beta3 or TGF beta or TGFbeta or TGF-beta or TGF*).mp. [mp=title, 770 abstract, original title, name of substance word, subject heading word, keyword heading word, protocol 771 supplementary concept word, rare disease supplementary concept word, unique identifier, synonyms]

$772 \quad 6 \quad 4$ or 5

7737 Milk, Human/ or Colostrum.mp. [mp=title, abstract, original title, name of substance word, subject 774 heading word, keyword heading word, protocol supplementary concept word, rare disease supplementary 775 concept word, unique identifier, synonyms]

7768 (breast milk or breast milks or human milk or milk or breast milk human or colostrum* or mature 777 milk or transitional milk).mp. [mp=title, abstract, original title, name of substance word, subject heading 778 word, keyword heading word, protocol supplementary concept word, rare disease supplementary concept 779 word, unique identifier, synonyms]

$\begin{array}{lll}780 & 9 & 7 \text { or } 8\end{array}$

78110 adolescent/ or child/ or child, preschool/ or infant/ or infant, newborn/ or infant, low birth weight/ 782 or infant, postmature/ or infant, premature/

78311 (child* or infant* or boy* or girl* or newborn*).mp. [mp=title, abstract, original title, name of 784 substance word, subject heading word, keyword heading word, protocol supplementary concept word, 785 rare disease supplementary concept word, unique identifier, synonyms]

$786 \quad 12 \quad 10$ or 11

$787 \quad 13 \quad 3$ and 6 and 9 and 12 
TABLE SII. Statistical analyses of association TGF- $\beta$ in HM and allergic outcomes

\begin{tabular}{|c|c|c|c|}
\hline Study & $\begin{array}{l}\text { Statistical analyses of association between groups and between TGF- } \beta \\
\text { in HM and allergic outcomes }\end{array}$ & $\begin{array}{l}\text { Data expression } \\
\text { and outcomes } \\
\text { reported }\end{array}$ & $\begin{array}{l}\text { Data transformation and adjustment to } \\
\text { potential confounders }\end{array}$ \\
\hline \multicolumn{4}{|c|}{ Interventional studies } \\
\hline $\begin{array}{l}\text { Rautava } \\
2002^{31}\end{array}$ & $\begin{array}{l}\text { The Student t-test for comparison of values between groups for normally distributed } \\
\text { data. } \\
\text { Mann-Whitney U-test for comparisons between groups for data of skewed distribution. } \\
\text { The Chi-squared test for comparisons of proportions between groups. }\end{array}$ & $\begin{array}{l}\text { Mean (95\%CI) } \\
\text { Median (IQR) }\end{array}$ & NR \\
\hline $\begin{array}{l}\text { Bottcher } \\
2008^{10}\end{array}$ & $\begin{array}{l}\text { Mann-Whitney U-test for unpaired analyses. } \\
\text { Spearman's rank order correlation coefficient test for correlations analyses. } \\
\text { Multiple logistic regression and ANOVA for analyses of multivariate relationships. }\end{array}$ & $\begin{array}{l}\text { Mean (range) } \\
\text { OR (95\% CI) } \\
r\end{array}$ & $\begin{array}{l}\text { Study treatment (placebo or } L \text {. reuteri) } \\
\text { Maternal atopy } \\
\mathrm{Na} / \mathrm{K} \text { ratios }\end{array}$ \\
\hline $\begin{array}{l}\text { Huurre } \\
2008^{29}\end{array}$ & $\begin{array}{l}\text { Mann-Whitney U-test, w2 test, the t-test for the baseline and clinical characteristics. } \\
\text { The association between infant sensitization and TGF- } \beta \text { tertiles (T1, T2 and T3) was } \\
\text { given descriptively. }\end{array}$ & $\begin{array}{l}\text { GM }(95 \% \mathrm{CI}) \\
\text { Probiotic/placebo } \\
\text { ratios }(95 \% \mathrm{CI})\end{array}$ & $\begin{array}{l}\text { * Logarithmically transformed } \\
\text { NR }\end{array}$ \\
\hline $\begin{array}{l}\text { Prescott } \\
2008^{30}\end{array}$ & $\begin{array}{l}\text { Mann-Whitney test for differences between the groups for non-parametric data. } \\
\text { Chi-square or Fisher's exact test for differences between the groups for dichotomous } \\
\text { data. Spearman or Kendall’s Tau for correlations. }\end{array}$ & $\begin{array}{l}\text { Median }(\mathrm{IQR}) \\
\tau\end{array}$ & $\begin{array}{l}\text { Factors with potential confounding effects were tested by } \\
\text { correlation analyses. } \\
\text { NR }\end{array}$ \\
\hline $\begin{array}{c}\text { Kuitunen } \\
2012^{12}\end{array}$ & $\begin{array}{l}\text { Mantel-Haenszel method for the association between HM variables and allergic } \\
\text { outcomes by the ages of } 2 \text { and } 5 \text { years in the treatment groups separately. } \\
\text { The Breslow-Day test for evaluation whether the association is different in the } \\
\text { probiotic group from that of the placebo group. }\end{array}$ & $\begin{array}{l}\text { GM }(95 \% \mathrm{CI}) \\
\text { OR }(95 \% \mathrm{CI})\end{array}$ & $\begin{array}{l}\text { * Logarithmically transformed } \\
\text { Assessed separately by treatment group if Breslow-Day } \\
\text { test indicated interaction }\end{array}$ \\
\hline $\begin{array}{l}\text { Ismail } \\
2013^{11}\end{array}$ & $\begin{array}{l}\text { The Student's t-test for normally distributed continuous data. } \\
\text { Mann-Whitney U-test was for skewed data. } \\
\text { Chi-squared test or Fisher's exact test for categorical data. } \\
\text { Logistic regression analyses. }\end{array}$ & $\begin{array}{l}\text { Mean }(\mathrm{SEM}) \\
\text { GM }(95 \% \mathrm{CI}) \\
\text { Median (IQR) }\end{array}$ & $\begin{array}{l}\text { * Skewed data } \log 10 \text {-transformed } \\
\text { Treatment group } \\
\text { Maternal allergic status }\end{array}$ \\
\hline $\begin{array}{c}\text { Simpson } \\
2016^{13}\end{array}$ & $\begin{array}{l}\text { Wilcoxon matched-pairs signed-rank test for comparison of the concentration at } 10 \\
\text { days and } 3 \text { months. } \\
\text { Linear regression for effect of probiotic supplementation on TGF- } \beta \text { concentrations. } \\
\text { Causal mediation analysis (paramed) for HM cytokines which were found to be altered } \\
\text { by probiotic supplementation. }\end{array}$ & $\begin{array}{l}\text { Median (IQR) } \\
\text { RR }\end{array}$ & $\begin{array}{l}\text { Maternal atopy } \\
\text { Maternal smoking during the first year of life } \\
\text { Presence of older siblings }\end{array}$ \\
\hline \multicolumn{4}{|c|}{ Observational studies } \\
\hline $\begin{array}{c}\text { Kalliomaki } \\
1999^{6}\end{array}$ & $\begin{array}{l}\text { The Fisher exact test or chi-squared test for differences in contingency tables. } \\
\text { The Kruskal-Wallis test for comparisons between the groups. } \\
\text { The Mann-Whitney U-test and Wilcoxon signed-rank test for comparisons between } 2 \\
\text { unpaired and paired groups, respectively. } \\
\text { Spearman rank correlation for correlation between } 2 \text { variables. }\end{array}$ & $\begin{array}{l}\text { Median (IQR) } \\
\% \\
r\end{array}$ & NR \\
\hline $\begin{array}{c}\text { Saarinen } \\
1999^{39}\end{array}$ & $\begin{array}{l}\text { ANOVA was used for multiple comparisons. } \\
\text { 2-tailed Student's t-test for comparisons between groups. } \\
\text { Spearman rank correlation test for correlations between measurement from colostrum } \\
\text { samples and from infants with CMA. }\end{array}$ & $\begin{array}{l}\text { Mean }(95 \% \mathrm{CI}) \\
r\end{array}$ & $\begin{array}{l}\text { * Logarithmically transformed } \\
\text { Maternal atopy tested, NS }\end{array}$ \\
\hline
\end{tabular}


The chi-square test for categorical variables, and Fisher's exact test for when the expected frequency for any cell was less than 5 .

Oddy Spearman nonparametric tests for correlation coefficients between cytokines.

$2003^{36}$ Contingency tables and the chi-square test for relationship between breastfeeding and wheeze in the first year of life. The relationship of the concentration of each cytokine in milk to wheeze was assessed by dividing the concentrations into tertiles with trend chi-square tests.

Logistic regression analyses to determine the odds for any wheeze associated with cytokine dose in milk.

A final categorization of concentration and duration of breastfeeding was calculated to reflect short or long duration of feeding (divided at the median in weeks) and low vs. medium-high cytokine concentration.

Savilahti Multivariate stepwise logistic regression analysis by the forward selection method.

Associations with symptoms of atopy and verified atopy were studied among the whole study group, those with long or short breast-feeding, and those with or without family history for atopy.

Rigotti Independent samples t-test for normally distributed variables and the Mann-Whitney

$2006 \quad$ U-test for variables not normally distributed for the differences between two unpaired groups.

Snijders ANOVA for comparisons of concentrations between groups.

Logistic regression analysis for association between cytokines and infant's atopic manifestations.

Extreme values of concentrations of cytokines were not excluded as these did not influence the results.

Tomicic Mann-Whitney U test for unpaired analyses.

Spearman's rank-order correlation coefficient test for correlation analyses.

The 2-test for categorical variables, and the Fisher's exact test for when the expected frequency for any cell was 5 .

Soto- Intra-class and Spearman correlation for associations of serum and whey immune Ramirez markers.

$2012^{25}$ Log-linear regression for associations between immune markers and asthma-like symptoms at age 6 months and ever asthma-like symptoms in the first year of life (supplemental material).

GEE was applied to predict repeated occurrence of asthma-like symptoms in infants at ages 6 and 12 months. In addition, models excluding infants who had both wheezy bronchitis and asthma-like symptoms were also ran.

Joseph Chi-square tests for subgroup comparisons of participant characteristics for binary and categorical variables. Wilcoxon Rank Sum (WRS) test cytokine levels comparison. Student's t-tests for comparison of continuous variables.

Logistic regression model for each atopic phenotype with the log-transformed TGF $\beta 1$ values and the variable of interest (infant race/ethnicity or maternal atopy), along with the interaction term.
Median,

Frequency (\%) in

groups

Mean $(95 \% \mathrm{CI})$ OR $(95 \% \mathrm{CI})$

GM $(95 \% \mathrm{CI})$

OR $(95 \% \mathrm{CI})$

Median (range)

Mean (SD)

OR $(95 \% \mathrm{CI})$

Median (range)

rho

RR (95\%CI)

GM $(95 \% \mathrm{CI})$

OR $(95 \% \mathrm{CI})$
NR

characteristics: smoking at 1 year (any vs. none), education ( $\leq 12$ vs. $>12$ years), history of physiciandiagnosed asthma (yes vs. no)

Offspring characteristics: sex, gestational age ( $<37$ vs. $\geq 37$ weeks), birth weight ( $\leq 6 \mathrm{lbs}$ vs. $>6 \mathrm{lbs}$ ), exposure to other children (presence of any older siblings or attendance at daycare with other children before 3 months)

* Logarithmically transformed

NR

The two groups of mothers were comparable for aging, alimentary habits, and pregnancy course.

Recruitment group (conventional vs. alternative)

Time interval between birth and HM collection (days) Total storage time in freezer until analysis (days)

Maternal characteristics: age, allergic history, season of breast milk collection, use of probiotics, infection (during week of HM collection)

Offspring characteristics: number of older sibling NR

Maternal characteristics: race, age at pregnancy, smoking during pregnancy, household cigarette use at ages 6 and 12 months, maternal history of asthma, eczema, rhinitis, consumption of antibiotics during pregnancy, vaginal infections/pelvic conditions during pregnancy

Offspring characteristics: gender, any respiratory infections at ages 6 and 12 months, season of birth

** FDR adjustment

* Logarithmically transformed

Maternal characteristics: atopic status

Offspring characteristics: race/ethnicity 
Orivuori

$2014^{37}$

Linear regression for association between levels of HM TGF- $\beta 1$ and exposures occurring up to month 2 of age.

Uni-/multivariate smoothed plots based on generalized additive regression modelling for graphical display of significant associations of dose variables and health outcomes.

Cox regression for the association between cytokine levels with age at onset of eczem Cox regression for the association between cytokine
and recurrent wheeze during the first 3 years of life.

Principal component analysis (PCA) was used to decompose the complex data set into fewer dimensions, reflecting the immunological intermediator correlation structure, and to extract patterns that describe the predominant variations in HM immune mediator levels.

To avoid the effect of reverse causality, a sensitivity analysis was performed excluding all children with eczema diagnosis before end of exclusive breastfeeding.

Ordinal logistic regression for the effect of probiotics.

Ramirez

Wilcoxon matched-pairs signed-rank test for comparison of concentrations at 2 time

$2016^{24}$ oints.

Linear regression for effect of probiotic supplementation on TGF- $\beta$ concentrations.

Causal mediation analysis (paramed) for breast milk cytokines which were found to be altered by probiotic supplementation.

GEE adjusting for within-participant effects using the regular maximum likelihood method for determination of the role of TGF- $\beta$ in scratching at ages 6 and 12 months.

Munblit Univariate analysis and correlation matrix, followed by multivariate analysis which included modelling, using least absolute shrinkage and selection operator (LASSO) and generalized linear model (GLM).

\section{GM $(95 \%$ CI)}

Quintiles

HR (95\% CI)

Median (IQR)

OR $(95 \% \mathrm{CI})$

RR $(95 \% \mathrm{CI})$ 
TABLE SIII. Associations between TGF- $\beta$ in human milk and allergic outcomes in children

\begin{tabular}{|c|c|c|c|}
\hline Reference & $\begin{array}{c}\text { Age at } \\
\text { outcome } \\
\text { assessment }\end{array}$ & $\begin{array}{l}\text { TGF- } \beta \text { isoform and } \\
\text { time } \\
\text { of collection }\end{array}$ & Associations between human milk TGF- $\beta$ and allergic outcomes \\
\hline \multicolumn{4}{|r|}{ Eczema (interventional studies) } \\
\hline Rautava $2002^{31}$ & 2 y.o & TGF- $\beta 1,2$ (MM) 3 mo & NS (data not shown) \\
\hline \multirow{2}{*}{ Bottcher $2008^{10}$} & 2 y.o & TGF- $\beta 1,2(\mathrm{C}) 3 \mathrm{~d}$ & NS (data not shown) \\
\hline & & TGF- $\beta 1,2$ (MM) 1 mo & NS (data not shown) \\
\hline \multirow[t]{2}{*}{ Prescott $2008^{30}$} & 2 y.o & TGF- $\beta 1$ (C) 3-7d & NS (data not shown) \\
\hline & & TGF- $\beta 1$ (MM) 1 and 3 mo & NS (data not shown) \\
\hline \multirow[t]{3}{*}{ Kuitunen $2012{ }^{12}$} & $\begin{array}{l}2 \text { y.o } \\
\text { Atopic E } 2 \text { y.o }\end{array}$ & TGF- $\beta 2$ (C) $0-3 d$ & $\begin{array}{l}\text { NS: OR, } 1.05 ; 95 \% \text { CI , } 0.61-1.79 \\
\text { NS: OR, 1.16; 95\% CI, 0.57-2.34 }\end{array}$ \\
\hline & 2 y.o & TGF- $\beta 2$ (MM) 3 mo & $\uparrow$ TGF- $\beta 2$ (MM) - $\uparrow$ higher risk of $E$ by the age of 2 years (OR, $2.30 ; 95 \%$ CI, 1.34-3.94) \\
\hline & Atopic E 2 y.o & & NS: OR, 1.51; 95\% CI, 0.77-2.96 \\
\hline \multirow[t]{2}{*}{ Ismail $2013^{11}$} & 1 y.o & TGF- $\beta 1$ (TM) $7 \mathrm{~d}$ & No E (451.3 (330.4725.4)) vs. E (450.4 (357.2798.7)): NS, $P=0.7 ;$ a $P=.9$ \\
\hline & & TGF- $\beta 1$ (MM) $28 \mathrm{~d}$ & No E (284.9 (200433.6)) vs. E (269.3 (200366.0): NS, $P=0.7$; a $P=0.6$ \\
\hline \multirow[t]{3}{*}{ Simpson $2016^{13}$} & 2 y.o & TGF $\beta 1-3$ (TM) $10 \mathrm{~d}$ & NS (data not shown) \\
\hline & & TGF $\beta 1-3$ (MM) 3 mo & NS (data not shown) \\
\hline & & & Eczema (observational studies) \\
\hline \multirow[t]{3}{*}{ Kalliomaki $1999^{6}$} & 1 y.o & TGF- $\beta 1,2(C) 0 d$ & $\uparrow$ TGF- $\beta 1$ - $\uparrow$ higher post-weaning onset of $E$ compared with no onset $(P=.0056)$ and pre-weaning onset $(P=.0008)$; \\
\hline & & & $\begin{array}{l}\uparrow \mathrm{TGF}-\beta 2 \text { - } \uparrow \text { higher post-weaning onset of } \mathrm{E} \text { compared with pre-weaning onset }(P=.015) \text { and comparable to nonatopic } \\
\text { control subjects. }\end{array}$ \\
\hline & & TGF- $\beta 1,2$ (MM) 3 mo & NS \\
\hline Savilahti $2005^{40}$ & 4 y.o & TGF- $\beta 1,2$ (C) $1-4 \mathrm{~d}$ & NS (data not shown) \\
\hline Snijders $2006^{41}$ & 1 y.o & TGF- $\beta 1(\mathrm{MM}) 1$ mo & $\begin{array}{l}\text { NS: } \\
\text { Low (2.0-166.9 pg/ml): aOR, 1.0; 95\% CI, reference; } n=30 \\
\text { Middle (166.9-248.4 pg/ml): aOR, 1.14; 95\% CI, 0.59-2.10; } n=32 \\
\text { High (248.5-1536.8): aOR, 1.00; 95\% CI, 0.53-1.91; } n=28 \\
P \text {-value for trend: aOR, 1.00; 95\% CI, } n=299\end{array}$ \\
\hline Rigotti $2006^{38}$ & $6 \mathrm{mo}$ & $\begin{array}{l}\text { TGF- } \beta 1(C) 3 d \\
\text { TGF- } \beta 1(\text { MM) } 1 \text { mo }\end{array}$ & 4/6 infants who developed E received milk with no TGF- $\beta 1$ in both C and MM. No statistical analysis has been performed. \\
\hline Tomicic $2010^{21}$ & 2 y.o & $\begin{array}{l}\text { TGF- } \beta 1,2(\mathrm{C}) 0-4 \mathrm{~d} \\
\text { TGF- } \beta 1,2(\mathrm{MM}) 1 \text { mo }\end{array}$ & NS (data not shown) \\
\hline Orivuori $2014{ }^{37}$ & $\begin{array}{l}2 \text { y.o } \\
4 \text { y.o }\end{array}$ & TGF- $\beta 1$ (MM) 2 mo & $\begin{array}{l}\text { NS: aOR, 0.86; 95\% CI, 0.65-1.14. } \\
\text { all NS (aOR, 95\% CI): Q1, 1.00; Q2, 0.95, 0.48-1.90; Q3, 1.12, 0.58-2.16; Q4, 0.64, 0.30-1.34; Q5, 1.00, 0.50-1.98. } \\
\text { NS: aOR, 0.83; 95\% CI, 0.63-1.08. } \\
\text { all NS (aOR, 95\% CI): O1. } 1.00 ; \text { O2, 0.77, } 0.40-1.51: 03,1.13,0.60-2.12 ; \text { O4 } 0.87 .0 .45-1.71 ; 05,1.10,0.57-2.09\end{array}$ \\
\hline Jepsen $2016^{33}$ & 3 у.о & TGF- $\beta 1(\mathrm{MM}) 1$ mo & NS: HR 0.89; 95\% CI, 0.72-1.10; P = 0.29; aHR 0.91; 95\% CI, 0.74-1.12 \\
\hline Soto-Ramirez $2016{ }^{24}$ & Scratching 1 y.o & TGF- $\beta 1(\mathrm{MM}) 21 \mathrm{~d}$ & $\begin{array}{l}\text { NS: } \\
\text { TGF- } \beta 1 \text { level } \geq 774.63: \text { RR, } 0.71 ; 95 \% \text { CI, } 0.48-1.05\end{array}$ \\
\hline
\end{tabular}




\begin{tabular}{|c|c|c|c|}
\hline & & & $\begin{array}{l}\text { Level 438.28-774.63: RR, 0.98; } 95 \text { \% CI, 0.73-1.31 } \\
\text { Level <436.28 - reference. }\end{array}$ \\
\hline \multirow[t]{3}{*}{ Munblit $2017^{35}$} & \multirow[t]{3}{*}{6 mo. } & \multirow{2}{*}{$\begin{array}{l}\text { TGF- } \beta 2 \text { (C) 0-6 d } \\
\text { TGF- } \beta 2 \text { (MM) } 1 \text { mo }\end{array}$} & NS: $\mathrm{a} P=0.66$ \\
\hline & & & $\uparrow T G F \beta 2$ (MM) - $\uparrow$ higher risk of E (aOR, 1.04; 95\% CI, 1.01-1.06) \\
\hline & & $\begin{array}{l}\text { TGF- } \beta 3 \text { (C) 0-6 d } \\
\text { TGF- } \beta 3 \text { (MM ) } 1 \text { mo }\end{array}$ & $\begin{array}{l}\text { NS: } \mathrm{a} P=0.087 \\
\text { NS: } a P=0.17 \\
\text { NS: } \mathrm{a} P=0.66\end{array}$ \\
\hline \multicolumn{4}{|c|}{ Atopic sensitization ( interventional studies) } \\
\hline Rautava $2002^{31}$ & 2 y.o & TGF- $\beta 1,2$ (MM) 3 mo & NS (data not shown) \\
\hline Bottcher $2008^{10}$ & 2 y.o & $\begin{array}{l}\text { TGF- } \beta 1(C) 3 \mathrm{~d} \\
\downarrow \text { TGF- } \beta 2(\mathrm{C})[<701 * *]\end{array}$ & $\begin{array}{l}\text { NS (data not shown) } \\
\downarrow \text { AS during first } 2 \text { years: } \mathrm{OR}, 0.3 ; 95 \% \mathrm{CI}, 0.1-0.9\end{array}$ \\
\hline & & TGF- $\beta 2(C)[>1400]$ & AS at 6 months: NS: aOR, 5.0; 95\% CI, 0.9-27 \\
\hline & & TGF- $\beta 1,2$ (MM) 1 mo & NS (data not shown) \\
\hline Huurre $2008^{29}$ & 1 y.o & TGF- $\beta 2(\mathrm{C}) 0 \mathrm{~d}$ & NS (data not shown) \\
\hline Prescott $2008^{30}$ & 2 y.o & $\begin{array}{l}\text { TGF- } \beta 1 \text { (C) 3-7 d } \\
\text { TGF- } \beta 1 \text { ( MM) } 1 \text { and } 3 \text { mo }\end{array}$ & $\begin{array}{l}\text { NS (data not shown) } \\
\text { NS (data not shown) }\end{array}$ \\
\hline Ismail $2013^{11}$ & 1 y.o & $\begin{array}{l}\text { TGF- } \beta 1(\text { TM) } 7 \mathrm{~d} \\
\text { TGF- } \beta 1(\mathrm{MM}) 28 \mathrm{~d}\end{array}$ & $\begin{array}{l}\text { NS (data not shown) } \\
\text { NS (data not shown) }\end{array}$ \\
\hline Simpson $2016^{13}$ & 2 y.o & $\begin{array}{l}\text { TGF } \beta 1-3(\mathrm{TM}) 10 \mathrm{~d} \\
\text { TGF } \beta 1-3(\mathrm{MM}) 3 \mathrm{mo}\end{array}$ & $\begin{array}{l}\text { NS (data not shown) } \\
\text { NS (data not shown) }\end{array}$ \\
\hline \multicolumn{4}{|c|}{ Atopic sensitization (observational studies) } \\
\hline Saarinen $19999^{39}$ & 1 y.o & TGF- $\beta 1$ (C) $1-4 \mathrm{~d}$ & $\begin{array}{l}\uparrow \text { TGF- } \beta 1(C)-\downarrow \text { SPT to CM }(r=-\mathbf{0 . 2 2 8}, P=.02) ; ~ \downarrow \text { SI to } \alpha \text {-casein }(r=-\mathbf{0 . 2 8 2}, P=.04) \text { and } \downarrow \text { SI to } \beta \text {-lactoglobulin }(r=- \\
\mathbf{0 . 3 4 7 , P = . 0 1 ) ;} \\
\text { NS: SIgE to CM }(r=-0.138, P=.18) \text {; SI to } \beta \text {-casein }(r=-0.241, P=.08) \text {. }\end{array}$ \\
\hline Bottcher $2003^{32}$ & 2 y.o & $\begin{array}{l}\text { TGF- } \beta 1,2 \text { (C) } 0-4 \mathrm{~d} \\
\text { TGF- } \beta 1,2 \text { (MM ) } 1 \mathrm{mo}\end{array}$ & $\begin{array}{l}\text { NS (data not shown) } \\
\text { NS (data not shown) }\end{array}$ \\
\hline Savilahti $2005^{40}$ & 4 y.o & TGF- $\beta 1,2$ (C) $1-4$ d & NS (data not shown) \\
\hline Snijders $2006^{41}$ & 2 y.o & TGF- $\beta 1$ (MM) 1 mo & $\begin{array}{l}\text { NS: } \\
\text { Low (2.0-166.9 pg/ml): aOR, 1.0; 95\% CI, reference; } n=17 \text {. } \\
\text { Middle (166.9-248.4 pg/ml): aOR, 1.19; 95\% CI, 0.52-2.74; } n=21 \text {. } \\
\text { High (248.5-1536.8 pg/ml): aOR, 0.51; 95\% CI, 0.21-1.24; } n=12 \text {. } \\
P \text {-value for trend: aOR, 0.13; 95\% CI, } n=200 \text {. }\end{array}$ \\
\hline Tomicic $2010^{21}$ & 2 y.o & TGF- $\beta 1,2$ (C) 0-4 d & $\begin{array}{l}\text { NS: In Sweden (median, 486; range, } 240-1400 \mathrm{pg} / \mathrm{mL} \text {, in non-sensitized vs. median 586; range, 365-1156, in sensitized infants; } \\
P=.11 \text { ). }\end{array}$ \\
\hline Joseph $2014^{34}$ & 3 у.о & TGF- $\beta 1$ (MM) 1 mo & $\begin{array}{l}\downarrow G M \text { in non-atopic mothers of infants with elevated vs. not elevated sIgE }(1347 \mathrm{vs.} 1651 \mathrm{pg} / \mathrm{ml} \text { respectively, } P=.047) \\
\uparrow G M \text { in atopic mothers of infants classified as allergen-specific IgE (2161 vs. } 1525 \mathrm{pg} / \mathrm{ml} \text { respectively, } P=.001) .\end{array}$ \\
\hline \multirow[t]{2}{*}{ Orivuori $2014^{37}$} & 4 y.o & TGF- $\beta 1$ (MM) 2 mo & $\begin{array}{l}\text { NS: aOR, 1.10; 95\% CI, 0.85-1.42. } \\
\text { Based on IgE cut-off 0.35Ku/l: } \\
\text { All NS (aOR, 95\% CI): Q1, 1.00; Q2, 1.10, 0.60-2.01; Q3, 1.03, 0.56-1.91; Q4, 1.46, 0.79-2.70; Q5, 1.76, 0.93-3.32. } \\
\text { All other cut-offs/ages: NS, } P>.05 \text {. }\end{array}$ \\
\hline & 6 y.o & & $\begin{array}{l}\text { NS: aOR,1.05; 95\%-CI, 0.82-1.36. } \\
\text { Based on IgE cut-off 0.35Ku/l: } \\
\text { All NS (aOR, 95\% CI): Q1, 1.00; Q2, 0.75, 0.41-1.35; Q3, 1.04, 0.56-1.93; Q4, 0.84, 0.46-1.53; Q5, 1.02, 0.55-1.89. } \\
\text { Based on IgE cut-off 3.5 kU/l (aOR, 95\% CI): Q1, 0.40, 0.18-0.90; Q2, 0.26, 0.11-0.61. } \\
\text { All other cut-offs/ages: NS, } P>.05 .\end{array}$ \\
\hline Munblit $2017^{35}$ & $6 \mathrm{mo}$ & $\begin{array}{l}\text { TGF- } \beta 1-3 \text { (C) } 0-6 \mathrm{~d} \\
\text { TGF- } \beta 1-3 \text { (MM) } 1 \text { mo }\end{array}$ & NS (data not shown) \\
\hline
\end{tabular}




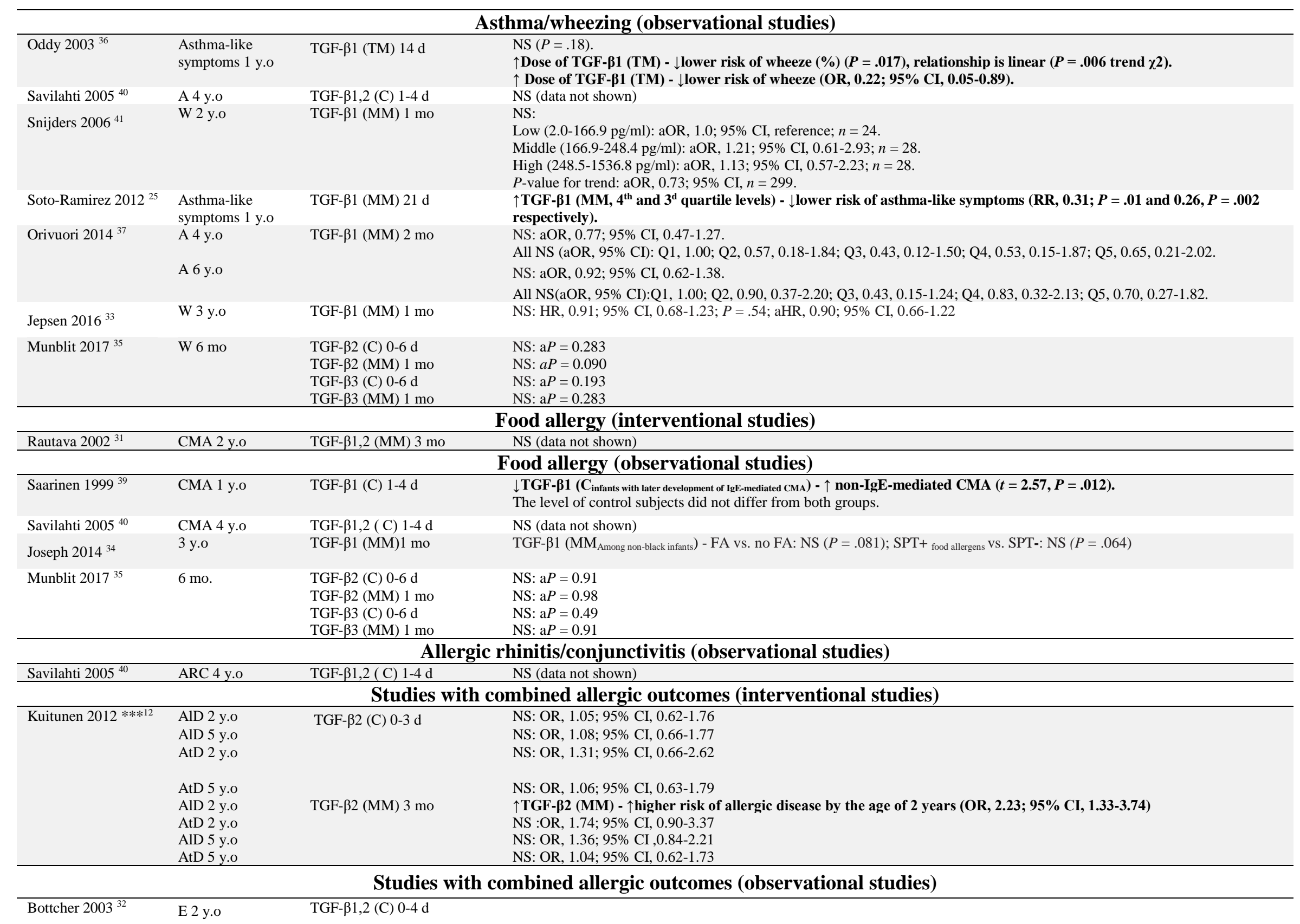


A 2 y.o

ARC 2 y.o
TGF- $\beta 1,2$ (MM) 1 mo

NS: the number of positive samples or the levels of the cytokines in C or MM and the development of either allergic symptom (P-values: .14 - .99).

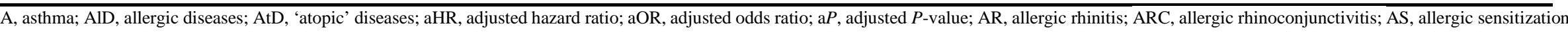

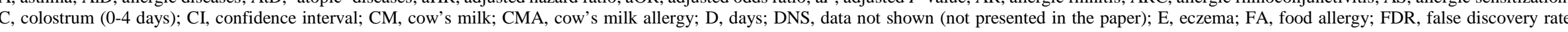

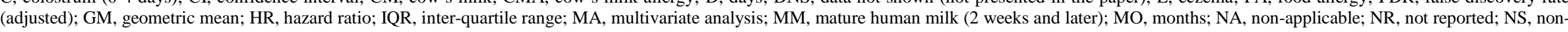

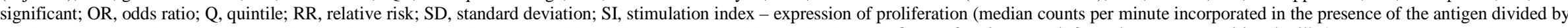
median counts per minute incorporated in the absence of the antigen); SPT, skin prick test; sIgE, specific IgE levels; TGF- $\beta$, transforming growth factor beta; TM, transitional milk (5-14 days); W, wheezing.

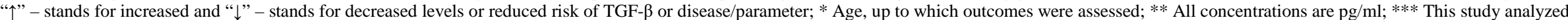
eczema separately and also combined allergic diseases for the analysis (eczema, food allergy, allergic rhinitis and asthma) and atopic (IgE-associated) allergic diseases. 